\title{
La construcción gubernamental de la contaminación ambiental: la política del aire para la ciudad de México, 1979.1996
}

\author{
José Luis Lezama \\ Centro de Estudios Demográficos \\ $y$ de Desarrollo Urbano \\ El Colegio de México
}

Resumen

Analizo la contaminación atmosférica, tal y como es conceptuada en los programas elaborados por las autoridades gubernamentales, como producto de una doble construcción. Por una parte, como producto de una construcción social, particularmente como una construcción ideológica y política. Construcción ideológica porque depende de la forma en que la sociedad valora, asume y vive el problema de la contaminación. Construcción política porque su emergencia pública está en función de factores tales como el ser valorado como elemento de reivindicación ciudadana, el ser valorado por la autoridad gubernamental como redituable desde el punto de vista de la gobernabilidad o de la legitimidad de la acción pública, y el ser valorado y vivido por los distintos agentes sociales como factor que afecta la distribución del ingreso y las relaciones de poder, cuando su inclusión como objeto de política se traduce en una distribución de costos. Por otra parte, 
como resultado de una construcción analítica llevada a cabo tanto por la autoridad científica, como por la gubernamental. Para esta última, en tanto elemento de diagnósticoen el que se sustentan los objetivos, metas, estrategias y acciones de los programas oficiales de combate a la contaminación del aire. Ambos tipos de construcciones están interrelacionados. Los diagnósticos y estrategias de acción de los programas de políticas públicas reflejan de muchas maneras el tipo de valoración social que poseen los problemas ambientales, los intereses políticos que derivan de la cuestión ambiental en los ámbitos gubernamentales y privados, el grado de conocimiento alcanzado, y el tipo y alcance de las reivindicaciones ciudadanas.

Consideraciones generales

Pensar la contaminación atmosférica del valle de México como un problema reducido a su descripción técnica, a su caracterización como problema de origen múltiple, o reducible a una simple racionalidad científica sobre la cual se construyen de manera objetiva las políticas, los programas y estrategias para su abatimiento, es desconocer los mecanismos verdaderos mediante los cuales se elaboran y ejecutan las políticas públicas. El problema de la contaminación atmosférica no es pues algo únicamente explicable por la razón técnica, el procedimiento intra o interdisciplinario, o por el simple recurso de la racionalidad científica. Este es un problema en el cual los factores sociales, ideológicos y políticos actúan, de manera muchas veces decisiva, en las distintas circunstancias de la emergencia de lo ambiental tanto en el plano de la conciencia ciudadana, como en el de los distintos momentos de la elaboración de las políticas. Así, es posible encontrar la presencia de estos factores tanto al simple nivel de la emergencia o marginación pública de la problemática ambiental, como también en su definición, diagnóstico y estrategias programáticas puestas en práctica por la autoridad gubernamental para su corrección y en el proceso de evaluación de los logros de los programas.

Es necesario destacar que aun cuando la presencia física y la explicación científica de la contaminación son una condición necesaria, no pueden considerarse como suficientes vara aue se haga de la contaminación objeto de un activismo político especial u objeto de una política y de estrategias programáticas dirigidas a su tratamiento. Si la presencia física de la contaminación fuera suficiente, los 4 millones de toneladas de contaminantes que se vierten anualmente a la atmósfera del valle de México (volumen difícilmente superable en alguna región del mundo) ya habrían dado lugar a un estado permanente de revuelta ambiental ciudadana en esta área del mundo. Más bien parece ocurrir lo contrario; esto es, una tendencia compartida por autoridades y ciudadanía a negar consciente o inconscientemente el problema, dada su magnitud y la imposibilidad de abatirlo drásticamente en el corto plazo. No es posible tampoco aludir únicamente a la objetividad del conocimiento adquirido sobre un problema ambiental específico; como es el caso de la contaminación del aire, para suponer su inclusión en las agendas ciudadana y gubernamental, o para esperar que de allí sea posible derivar un activismo ambiental vigoroso $\mathrm{o}$ medidas gubernamentales efectivas. Los problemas ambientales, lo mismo que todos aquellos que son objeto de las políticas públicas, atraviesan por un proceso de construcción social más amplio, lo que les permite transitar de su condición de "problemas físicos reales ${ }^{\mathrm{n}}$ a problemas objetos de la atención por parte de la agenda gubernamental (Crenson, 1972; Adams, 1994; Portney, 1992). Es preciso el tránsito, para poner el ejemplo que me interesa destacar, del estado físico de la contaminación del aire, a su estado social (analítico, ideológico y político), para que sea susceptible de una demanda reivindicativa o de una política pública específica.

Lo anterior supone la incorporación de lo ambiental, y en este caso específico del problema del aire, en el "paquete cultural ${ }^{\mathrm{n}}$ comprendido por las llamadas condiciones de bienestar de una comunidad concreta, para que ésta lo integre en su sistema de valores; hace falta también su incorporación en el "paquete de las reivindicaciones sociales ${ }^{\mathrm{n}}$ para que tal comunidad esté dispuesta a negociar su inclusión en las demandas ciudadanas o sociales en general, y hace falta su inclusión en el "paquete de las demandas políticas" para que sea integrado en la agenda gubernamental como elemento de gobernabilidad y legitimidad.

Se requiere analizar este proceso de construcciónsocial de los problemas para poder dar cuenta, analíticamente, de la incorporación de una problemática específica (como es el caso de la del aire) en la agenda gubernamental. Esta finalmente refleja la forma y el grado en el que la comunidad ha integrado la problemática ambiental en su sistema de valores y en sus expectativas de bienestar. 
Una vez como parte integrante de las condiciones de bienestar, las comunidades están en la posibilidad de plantearse los niveles aceptables y el precio que quieren o pueden pagar por cada uno de estos elementos de que se forma el "paquete" de sus condiciones de bienestar social. Es esto lo que está detrás del sistema de preferencias sociales mediante el cual los grupos sociales jerarquizan sus problemas, y es lo que le asigna su lugar a problemas como el del medio ambiente en relación con problemas considerados como objetos de preocupación, como son los casos del empleo, la seguridad, la educación, la vivienda, etcétera. Es sólo en este contexto que puede explicarse la incorporación de la problemática del aire en la agenda gubernamental, y el grado de compromiso en la búsqueda de soluciones, tanto por parte de la comunidad como del gobierno. La forma misma en la que la sociedad construye el problema ambiental tiene un efecto directo en su construcción en la agenda gubernamental, particularmente en cuanto a los diagnósticos y estrategias establecidos en los programas oficiales.

La calidad del medio ambiente es, en distinto grado, un elemento de bienestar para muchas comunidades; la diferencia entre unas y otras es el grado en el que su deterioro es aceptado. En algunas naciones desarrolladas el grado de tolerancia social es menor que el que existe en otras. Esto ocurre así por diversos motivos. Algunos autores sostienen que las diferencias existentes entre el mayor interés o preocupación en las naciones desarrolladas por lo ambiental, deriva del hecho de que éstas pueden dirigir su atención a una necesidad regularmente considerada como "secundaria", como es el caso de la calidad del medio ambiente, una vez que las necesidades "primarias" han sido cubiertas. En este orden de argumentación, el menor interés que existe en los países pobres por el deterioro ambiental, sería explicable porque ahí no han sido satisfechas las necesidades más elementales de la población. Estas argumentaciones desconocen ese proceso social de construcción de unas y otras necesidades al que vengo haciendo referencia. En este sentido podemos hablar también de proceso ideológico y político de construcción de ese paquete de elementos que integran la calidad de vida y el bienestar en unos y otros países, de tal suerte que en algunas sociedades podamos hablar de ocultamiento de un conjunto de problemas, que únicamente emergen a la conciencia mediante la generación de un conocimiento crítico y socialmente comprometido, o bien cuando los problemas ambientales revisten formas catastróficas o cuando sus magnitudes lo hacen emerger con toda obviedad. La inclusión de nuevos componentes en el paquete de las condiciones del bienestar es también de naturaleza ideológica y política; esto significa que lo ambiental es incluido o excluido del paquete del bienestar de acuerdo con el juego de fuerzas desplegado en torno a los recursos económicos y políticos de una comunidad.

En países como México el medio ambiente sufrió un proceso de deterioro severo desde los inicios de la etapa industrializadora que arrancó en los años cuarenta. El aire, en especial (aunque no únicamente), se vio sometido a una drástica disminución de su calidad en los principales centros de actividad industrial, siendo esto más agudo en las tres principales zonas metropolitanas del país. No obstante, esto no se tradujo directa ni proporcionalmente en el surgimiento de una conciencia ambiental más activa que incluyera su calidad como un elemento básico del bienestar y de reivindicación ciudadana.

A principios de los años setenta la cuestión ambiental emerge como bandera ideológica gubernamental en el contexto de un movimiento ambientalista internacional que había llevado a las Naciones Unidas a organizar la llamada "Cumbre de la Tierra" en Estocolmo, en 1972. Lo ambiental nace en México como bandera ideológica del partido oficial, no como una demanda ciudadana. Esto no significa que los problemas ambientales no fueran importantes en el país, pero da cuenta de un horizonte de posibilidades reivindicativas atado a las necesidades gubernamentales y partidistas de legitimidad. Estas eran limitadas a su utilidad como bandera de campaña política y como forma de legitimidad de la acción gubernamental en el ámbito internacional y en algunos sectores de la sociedad nacional. Dicha incorporación "desde arriba" de lo ambiental en la agenda gubernamental, explica la escasa efectividad de las acciones emprendidas, así como la pobre construcción de la problemática en los programas de gobierno. La definición del problema ambiental y su incorporación en la agenda oficial como producto único de ese monopolio que ejerce el gobierno en el planteamiento de las políticas, ha dado resultados muy pobres en términos del mejoramiento de la calidad del medio ambiente porque los problemas así construidos son ajenos a los que la comunidad percibe y vive, o al menos a aquellos por los cuales se comprometería en mayor medida. 
Mediciones de la contaminación atmosférica (1989-1996)

El análisis de la contaminación y la práctica de la planeación atmosférica en el valle de México se hicieron más rigurosos con la elaboración del Inventario de Emisiones de 1989, el cual constituyó la principal herramienta para realizar el Programa Integral Contra la Contaminación Atmosférica de 1990 (PICCA), que inicia una etapa de mayor profesionalización en los programas para abatir el problema de la contaminación atmosférica en el valle de México. La construcción de un segundo inventario con datos para 1994 representó un esfuerzo de gran significado para el estudio del problema del aire, y una herramienta básica para el Programa para Mejorar la Calidad del Aire del Valle de México en 1996.

De acuerdo con el inventario de 1989, el valle de México recibía anualmente 4,356,391 toneladas de sustancias contaminantes al año, las cuales se debían en un $76.7 \%$ al transporte, en un $8.4 \%$ a industria y servicios (incluyendo sector energía), y en un $15 \%$ a la degradación ecológica. Los datos del Inventario de Emisiones de 1994 dan cuenta de un volumen total de contaminantes vertidos en la atmósfera de 4,009,629 toneladas anuales. De acuerdo con este último inventario, el transporte es responsable de $75 \%$ de ese total, la industria y servicios ocasionan 13\%; y vegetación y suelos, $12 \%$.

No obstante, la participación de los sectores mencionados es diferencial según el tipo de contaminante. Así, por ejemplo, en 1989 el sector industrial y de servicios aportaba $78.2 \%$ de todo el bióxido de azufre $\left(\mathrm{SO}_{2}\right)$ lanzado a la atmósfera, correspondiendo solamente $35.5 \%$ a PEMEX y a las termoeléctricas; mientras que el sector transporte aportaba $21.7 \%$ de este contaminante. En 1994 el inventario le atribuye $73 \%$ del SO, al sector industria y servicios, con la diferencia de que la participación del sector PEMEX y generación de energía eléctrica prácticamente desaparece al ser sólo de $\mathbf{0 . 2 \%}$; el sector transporte contribuía con $26.8 \%$. Es importante destacar que entre el inventario de 1989 y el de 1994, el SO disminuyó 78\%. En lo referente a los óxidos de nitrógenos (NOx) en el inventario de 1989 el principal responsable de éstos era el sector transporte, con $75.4 \%$, mientras que el sector industria y servicios generaba 24\%; según el inventario de 1994 estas proporciones fueron de $71.3 \%$ para el sector transporte, y de $28.6 \%$ para industria y servicios. En el inventario de 1994 este contaminante registra un volumen $27 \%$ menor respecto al de 1989 no obstante, en 1994 el subsector energía aparece con un incremento de $82 \%$ en sus emisiones de NOx respecto a 1989. En el caso de los hidrocarburos (HC), 12.5\% de las emisiones en 1989 provenían del sector industria y servicios, $52.5 \%$ del transporte y $35 \%$ de causas naturales. Según el inventario de 1994 estas proporciones se presentaron de la siguiente manera: $42 \%$ de las emisiones de $\mathrm{HC}$ fueron producto de las actividades industriales y de servicios, $54 \%$ del sector transporte, y $4 \%$ tuvo causas naturales. Separando al sector energía tenemos una drástica reducción entre 1989 y 1994 de acuerdo con los dos inventarios, al pasar de $5.5 \%$ a una proporción de $0.2 \%$. No obstante, este contaminante presenta serios problemas. Si pudiéramos comparar (lo cual, según nos advierten los autores, no es del todo posible) el inventario de 1989 con el de 1994, obtendríamos que en el subsector energía los HC habrían disminuido $99 \%$, mientras que en el de industria y servicios (excepto energía) habría aumentado $975 \%$; en el transporte el aumento entre uno y otro inventario sería de $\mathbf{8 8 \%}$, y las fuentes naturales habrían disminuido 81 por ciento.

\section{Los programas gubernamentales para el combate a la} contaminación (1979-1996)

En el periodo que va de 1979 a 1996 el gobierno puso en marcha tres programas para enfrentar el problema de la contaminación del aire en el valle de México: 1) "Programa Coordinado para Mejorar la Calidad del Aire en el Valle de México 1979-1982" (PCMCA) de 1979; 2) "Programa Integral contra la Contaminación Atmosférica de la Zona Metropolitana de la Ciudad de México" (PICCA) de 1990; y 3) "Programa para Mejorar la Calidad del Aire en el Valle de México, 1995-2000" (PROAIRE) de 1996. Durante los años ochenta se establecieron diversas medidas, algunas con fuerte impacto en términos de la calidad del aire de la región. No obstante, aquí éstas sólo serán mencionadas marginalmente, concentrándonos en el análisis de los tres programas más importantes, en la medida en que ellos constituyen estrategias de política de mayor alcance que las poseídas por programas más específicos.

Entre la fecha de publicación del primer programa y la del último, ocurren cambios fundamentales, tanto en la problemática ambiental del valle de México, como en las condiciones económicas y sociopolíticas en las que aquélla tiene lugar. En el primer caso, la composición de las sustancias emitidas a la atmósfera sufrió importantes modificaciones, las cuales provenían de los cambios en los combustibles utilizados por las diversas actividades productivas 
Y de consumo, de las transformaciones en las tecnologías utilizadas en las mismas y de los cambios operados en la composición del producto. La conceptuación de estas modificaciones es fundamental para la elaboración de las políticas del aire. No obstante, los diagnósticos de los programas gubernamentales no dan cuenta de esta situación cambiante, por lo que las propuestas de acción se rezagan respecto a la evolución de los fenómenos. Todo el sistema de programación ambiental de 1979 a 1996 muestra una insensibilidad especial a la dinámica real del problema ambiental, por lo que mientras éste se ve sujeto a un intenso proceso de cambio, las propuestas de política se obstinan en repetir un proyecto analítico y programático que nace con el programa de 1979 y que se caracteriza por plantear una noción de los problemas atmosféricos y un conjunto de propuestas de acción al margen del contexto económico, social y político en el que se sitúan estos problemas sobre los que se desea intervenir.

La construcción del problema ambiental por parte del sector gubernamental ha padecido de un estancamiento analítico, lo cual se refleja en la incapacidad de los programas oficiales para trascender esa visión estrecha de lo ambiental y de la contaminación del aire que se hace oficial con el programa de 1979. Mediante ella se acota el ámbito de análisis y de intervención gubernamental al plano de la existencia físico-técnica de los problemas, dejándose intactos los planos de lo económico, de lo social y de lo político, en los que se sitúan estos problemas objetos de la acción del gobierno. La causa del estancamiento se explica, en parte, por la práctica de un sistema de planificación monopólica tanto en la etapa de formulación de políticas, como en la de su puesta en operación. Los hallazgos de la comunidad científica no llegan a las oficinas de gobierno, y cuando lo hacen es sólo en la medida en que convalidan la visión gubernamental; las instancias institucionales creadas para hacer intervenir a los distintos sectores de la comunidad, sólo son convocadas para validar diagnósticos ya elaborados y decisiones ya tomadas; la participación ciudadana en los distintos momentos de la planeación no existe, practicándose sólo una versión manipuladora de ella que pretende involucrar a la ciudadanía en la visión gubernamental del problema y en la versión oficial de las soluciones. Lo ambiental aparece como una construcción unilateral, y particularmente dirigida a satisfacer las necesidades de legitimación de la acción pública.

Las diferencias entre unos y otros programas son más de forma que de fondo. La concepción general formulada por el PCMCA (de 1979) sigue sosteniéndose aún en el programa más reciente. El plan analítico y programático planteado por el PCMCA se ha convertido en una especie de techo analítico infranqueable para el sistema de programación posterior. Las únicas diferencias contenidas en el PICCA (1990) y en PROAIRE (1996) consisten en llevar hasta sus últimas consecuencias el programa original, y en hacer más amplio y detallado el desglose de las metas y las acciones concretas. Más allá de estas diferencias operativas, los últimos programas revalidan aquella concepción que privilegia y ásla la dimensión físico-química y técnica, demostrándose una especial incapacidad para ascender al * plano de lo social y lo político.

En el último programa (PROAIRE, 1996) la forma discursiva se independiza de todo contenido. El propósito es adecuar la acción planificadora gubernamental al discurso ambientalista internacional y a las emergentes aspiraciones de una ciudadanía cada vez más informada y más consciente del deterioro de su calidad de vida por obra de la disminución de la calidad del aire. Los cambios en las características de la contaminación y en el contexto social ya mencionado, que la agenda gubernamental no logra asimilar, en esencia tienen que ver también con la mejor calidad de los conocimientos generados y con la internalización de la problemática ambiental en el esquema de preferencias de la sociedad mexicana. La política del aire se hizo más agresiva porque también la ciudadanía devino más consciente de la severidad de un daño ambiental que repercute cada vez más en la salud, la economía y la vida cotidiana de diversos sectores de la población. No obstante, una ciudadanía más consciente y activa junto con una política del aire más agresiva, no derivan automáticamente en una mayor efectividad de los programas gubernamentales. A lo sumo, crean las condiciones para una mayor presencia, vigilancia y presión por parte de la sociedad en la aplicación de la estrategia escogida. Que esta estrategia sea la correcta no depende de la voluntad ciudadana, ni del activismo discursivo gubernamental, sino de una construcción adecuada de los problemas atmosféricos, de una voluntad social y gubernamental de llevar las metas ambientales adelante, y de la existencia o capacidad para crear condiciones sociales y políticas, por parte de los distintos agentes sociales, para poner en operación programas que implican una redistribución de los costos y beneficios públicos y privados asociados al combate de la contaminación.

El PCMCA de 1979 nace en un contexto social poco favorable para lograr el tránsito de la contaminación física -indudablemente existente en esa época- a la contaminación bajo su dimensión social. 
No bastaban, como ya se ha mencionado, los 4 millones de toneladas de contaminantes vertidos en la atmósfera para hacer emerger lo ambiental como problemática social y como objeto de atención de las políticas públicas. No bastaba esta presencia porque no existía de manera paralela un movimiento ambientalista con presencia amplia; los hallazgos de la comunidad científica aún no eran suficientes para analizar las causas o los efectos de la contaminación; el problema del plomo en la atmósfera no había sido suficientemente documentado y difundido; y los estudios de las consecuencias en la salud no habían llegado al punto de despertar la conciencia colectiva. En síntesis, no existía $\longrightarrow$ al menos no de manera significativa - el tránsito de la condición de riesgo físico a riesgo social; este último, al resultar de su incorporación a una tabla de valores sociales, propicia su inclusión en el paquete de necesidades y reivindicaciones básicas de la comunidad.

El manejo de la cuestión ambiental por la Secretaría de Salubridad, no sólo da cuenta del enfoque de salud pública del problema, sino también de la baja capacidad de maniobra de quienes deciden la implantación de los programas. En este sentido destacan el reducido margen de maniobra, los escasos recursos financieros y profesionales, y un enfoque con el sesgo de la medicina tradicional. No existe, en el programa de 1979, un intento por construir lo ambiental con legalidad propia, sino únicamente como aquella rama de la medicina que tiene que ver con la salud pública. No existe la vinculación de las propuestas ambientales con las de carácter económico, ni intento alguno de cuestionamiento de los modelos de desarrollo y su relación cón la degradación ambiental.

Si consideramos el problema de la contaminación atmosférica tal y como es pensada y combatida en el PICCA, y lo comparamos con el PCMCA, suponiendo que ambos correspondan a las condiciones generales de su época, podemos afirmar que los once años transcurridos entre uno y otro programas dan cuenta de cambios sustantivos en la problemática de la contaminación atmosférica del valle de México, lo cual se traduce en una lectura diferente (más científica, más política y también más ideológica) por parte de los distintos sectores de la sociedad involucrados en ella, y da cuenta del minucioso proceso de construcción social de la problemática ambiental. En este proceso fue fundamental, desde luego, tanto el aumento del volumen y la composición de la contaminación atmosférica, como los progresos logrados en el conocimiento y el papel de los medios.
Existe en este sentido una mayor y más amplia medición y caracterización de algunos de los contaminantes, particularmente de aquellos clasificados por la comunidad internacional como los "contaminantes criterio", y la acumulación de un número significativo de estudios de caso sobre la relación contaminaciónmorbilidad. Por otra parte, la problemática ambiental se ha convertido en bandera de reivindicación de grupos ecologistas y diversos sectores de la sociedad, al mismo tiempo que este discurso ha ingresado al lenguaje oficial de la planificación. En 1985 tiene lugar un devastador terremoto en la ciudad de México y se produce, a consecuencia de sus efectos y de la inacción gubernamental, una gran movilización social. El medio ambiente aparece con una fuerza que no había poseído anteriormente en el plano de la conciencia. colectiva, destacando, sobre todo, el nacimiento de diversas organizaciones ecologistas. Desde el punto de vista ideológico, los temas de la sustentabilidad y del medio ambiente poco a poco han ido penetrando el esquema de los valores sociales, interviniendo paulatinamente como elemento de calidad de vida. Los medios de comunicación, y en parte el sistema educativo, llevan el tema ambiental al escenario público, haciendo emerger una opinión pública cada vez más interesada en el medio ambiente, ya sea porque es afectada por su degradación o porque es conmovida por la información cada vez más amplia que se divulga acerca de los distintos peligros a los que se enfrenta a consecuencia del manejo irresponsable de los recursos naturales.

En 1979, cuando se elabora el PCMCA, el volumen de contaminantes parece similar al registrado en 1994. Desde luego que los 4 millones de toneladas de 1994 corresponden a una medición más precisa, mientras que los de 1979 resultan sólo una estimación muy ligera. También es cierto que la composición en uno y otro inventario es muy distinta. En 1994 el plomo de la atmósfera es significativamente menor. No podemos decir, sin embargo, que el resto de los contaminantes en términos de efectos en la salud y de variedad de sustancias tóxicas sea más favorable en uno u otro de los cortes temporales establecidos. No obstante, la conciencia gubernamental y ciudadana de la magnitud del problema no existía en 1979 con la fuerza que posee en 1996. El componente social de la contaminación, en el caso del último programa del aire, le ha dado legitimidad a su componente físico, algo que no ocurría en el programa de 1979 y para años anteriores.

Entre 1979 y 1996 ocurren cambios significativos en el país y en el valle de México en los distintos niveles de que se integra la 
cuestión ambiental en general y la problemática del aire en particular. La población de la zona metropolitana aumenta de manera importante; el número de industrias y establecimientos de servicios también se incrementa; la composición del producto sufre transformaciones; los insumos se modifican; los combustibles son sometidos a un intenso proceso de reformulación; los agentes económicos sufren reacomodos importantes, y los agentes políticos enfrentan situaciones nuevas y cambiantes que los lleva a nuevas formas de consenso social. Es este también un periodo de nacimiento de todo un aparato institucional en el que lo ambiental entra de lleno en el discurso oficial, y la práctica de la planificación y gestión ambiental se oficializa. El gobierno de la ciudad de México, que inicia los años ochenta sin contar con un organismo directamente establecido para el manejo de la cuestión ambiental, crea primero una dirección de ecología y, después, una secretaría del medio ambiente; instituciones éstas que surgen al abrigo de otras de carácter nacional, movidas también por la misma necesidad de enfrentar los diversos problemas ambientales nacionales. Pero son estos también años de cambios en el plano de la conciencia ciudadana hacia lo ambiental, de una generación de conocimientos sin precedentes en todos los aspectos que lo integran $y$, particularmente, de un deterioro de las condiciones materiales y sociales en la calidad de vida de muchos sectores de la población.

PROAIRE nace en 1996 en un contexto más favorable. La medición misma de la contaminación atmosférica es más precisa, de lo cual dan cuenta los inventarios de emisiones de 1989 y de 1994. La posibilidad de profundizar en el análisis se debe tanto a la vasta cantidad de información generada en los últimos años, como a la gran producción de conocimientos de los cuatro o cinco años anteriores a PROAIRE y a su Inventario de Emisiones (1994), con el cual se precisan las mediciones y se podría apuntar hacia una evaluación de las estrategias del PICCA; se avanza en el conocimiento de los factores meteorológicos; se plantean nuevas normas; y se alcanzan, en 1992, niveles históricos de contaminación en algunas sustancias como el ozono (además de vivirse el ambriente ecologista internacional que rodea a la Cúmbre de Rio). Ocurre también un acontecimiento con importantes repercusiones en las emisiones de contaminantes: el cierre de la refinería 18 de Marzo en Azcapotzalco, medida política no prevista y ni siquiera insinuada en el PICCA, realizada en el contexto de las negociaciones del TLCAN.
Crítica a la construcción gubernamental de la contaminación ambiental

A continuación analizo la construcción de la problemática del aire, y las estrategias diseñadas para su tratamiento programático en el valle de México, tal y como es realizada por los tres programas que sucesivamente se han puesto en práctica entre 1979 y 1996. Parto del supuesto de que en esta construcción llevada a cabo por la autoridad gubernamental y para los fines de la misma, de alguna manera se refleja el balance de las visiones, construcciones y valoraciones, mediante las cuales la sociedad vive $y$ asume sus problemas ambientales. Los programas reflejan de alguna manera las condiciones en las que se construyen socialmente los problemas en su momento.

Primero enumero los factores que cada uno de los programas considera como los más relevantes para explicar la contaminación atmosférica. Procedo a una clasificación de estos factores en dos grupos: unos que corresponderían a un primer nivel de análisis, que incluye los de orden físico-químico-técnico; otro grupo de factores correspondería a un segundo nivel de análisis, que incluye a los de orden sociopolítico. Parto del principio metodológico de que estos niveles poseen por sí mismos un grado específico de eficacia explicativa, pero que ubicados en el plano de las políticas públicas, el nivel correspondiente a lo social posee una eficacia mayor en la medida en que las relaciones más relevantes a ser explicadas y modificadas para la puesta en práctica de las políticas, son de naturaleza social y política. Este ordenamiento analítico no le resta importancia al primer nivel, lo que hace es relacionar ambos niveles y quitarle el carácter autorreferencial a cualquiera de ellos, asignándoles grados relativos y no absolutos de causalidad. Un factor es clasificado en el nivel 1 cuando alude a elementos de contaminación de naturaleza físico-química, o cuando su ámbito explicativo se limita a elementos técnicos, sin buscar relaciones más allá de este nivel de existencia. Otro factor lo califico como de nivel 2 cuando hace intervenir elementos que trascienden el nivel uno, proponiendo los vínculos causales entre condiciones de existencia de orden físico-químicotécnico con determinaciones sociales o en sus vínculos con fuerzas políticas; en cierta medida, a este nivel corresponden las personificaciones en el plano social y político de los factores expresados en el nivel 1. Es necesario aclarar en este contexto que no basta con que un programa señale la incorporación de elementos socioeconómicos para que sean incluidos en el nivel 2; es necesario que establezca relaciones precisas con relaciones sociales y fuerzas políticas 
específicas, o que dé cuenta de la personificación de los factores de nivel 1 en el plano de las relaciones sociales. Estos agentes deben ser ubicados en el contexto de aquello que los convierte en tales agentes, esto es, como portadores de recursos que influyen o deciden la forma específica que asume algún fenómeno ligado a la contaminación del aire. En muchas ocasiones los programas hablan de factores socioeconómicos, pero se limitan a sus expresiones técnicas físicas. Por ejemplo, tiende a tomarse como elemento socioeconómico laconcentración industrial,poblacional, etcétera. Es decir, la consecuencia de una relación es tomada como la relación misma, y a ello se, le atribuyen las virtudes de lo socioeconómico. No está por demás decir que los límites entre los niveles 1 y 2 son arbitrarios y únicamente deben ser considerados como herramientas de análisis. En la realidad tales fronteras no existen o son muy difíciles de establecer.

Se trata de analizar el procedimiento analítico mediante el cual cada programa ordena y jerarquiza los factores causales que hace intervenir para explicar la contaminación del aire. A continuación analizo las estrategias programáticas y su relación y congruencia con la construcción del problema ambiental. El paso siguiente es la comparación que realizo con un modelo o esquema ideal en el que incluyo aquellos elementos que considero deberían hacerse intervenir en la construcción del problema y en una propuesta de política más objetiva y con mayor grado de efectividad. Clasifico los tres programas en la medida en la que se acerquen o se alejen de este modelo. No afirmo que éste sea aplicable a la realidad, de allí también su carácter ideal. Para ello se requerirían condiciones técnicas y sociopolíticas que no existen. Señalo, eso sí, que una política congruente con una noción social de lo ambiental podría ser calificada como más o menos adecuada en la medida en la que se acerque o se aleje de este modelo.

De todas maneras, el recurso a este modelo tiene sólo una finalidad analítica, cuyo propósito es ordenar y evaluar la objetividad, la lógica, la congruencia y la viabilidad de los diagnósticos y de las propuestas programáticas de los tres programas aquí analizados.

\section{a) Programa Coordinado para Mejorar La Calidad del Aire en el Valle de México, 1979 (PCMCA)}

En 1979 el gobierno de la ciudad de México publicó el PCMCA, en el cual, en términos generales, se recogían las recomendaciones del grupo internacional de expertos convocado por el gobierno de la ciudad de México en noviembre de 1978 para analizar el problema de la contaminación del aire en esta región del país. Este programa, que no incluye el diagnóstico sobre el que se sustenta su estraregia programática, hace intervenir como factores explicativos de la contaminación atmosférica del valle de México elementos de orden natural y geográfico, a los cuales sobrepone como elemento de causalidad adicional el carácter concentrador de las diversas actividades humanas que tienen lugar en la zona. En este sentido se enumeran, como causas de la contaminación, las concentraciones demográfica, industrial y de automotores.

El problema de la contaminación atmosférica es construido particularmente en el nivel de análisis 1 de acuerdo con el esquema propuesto, incluyendo consideraciones correspondientes al nivel 2 pero sin asignárseles a éstas una relevancia explicativa. En este sentido, las características físico-químicas-técnicas de la contaminación explican por sí mismas el problema atmosférico del valle. Por ello los problemas del aire aparecen como resultado de una inmensa concentración de sustancias contaminantes emitidas en un ámbito geográfico y climatológico, coincidentes con un tipo de suelos, propicio a la degradación y emisión de polvos. Bajo estas condiciones, y ante la ausencia de factores naturales dispersantes, las sustancias emitidas no sólo se concentran en la atmósfera del valle sino que originan procesos y reacciones químicas que, combinados con otras características físicoquímicas, precipitan las situaciones de contingencia ambiental.

Por un lado aparecen las características técnicas de la flota vehicular y de la planta industrial y de servicios; por otro, el tipo y calidad de combustibles utilizados; éstos se ubican en el nivel 1 porque, en conjunción con los factores de orden físicoquímico y naturales en general, constituyen por sí mismos los principales elementos que explican, de acuerdo con este programa, la contaminación atmosférica de la región. El PCMCA hace intervenir algunos elementos que podrían ser incluidos en el nivel 2; tales son los casos de la mención de la concentración de actividades socioeconómicas y elementos de consumo, como por ejemplo el uso inmoderado del automóvil. No obstante, esta inclusión en el PCMCA de factores 
sociales y económicos no posee una capacidad explicativa similar o mayor a las del nivel 1. El consumo y la concentración de actividades, factores que bajo otro marco interpretativo podrían aparecer como de naturaleza social y cualitativa, se reducen a un agregado más, con la lógica de añadir factores y no con la de explicar fenómenos.

La limitación de esta construcción del problema ambiental es que no logra establecer ningún orden analítico jerárquico que permita establecer causalidades y definir grados de eficacia explicativa entre los dos niveles. Una noción de lo social que excluye agentes, distribución de recursos y relaciones de poder, no cumple los requisitos de análisis mínimos para servir de sustento al proceso de diseno de una política pública. Estas políticas reasignan costos, por lo tanto redistribuyen recursos y, al hacerlo, repercuten en las relaciones entre agentes; es decir, modifican relaciones de poder. Las consideraciones de orden socioeconómico que incluye este programa aparecen como un añadido más; como recurso discursivo, no como elemento analítico.

El PCMCA plantea de manera pragmática sus objetivos y metas. Éstas se acotan a la manifestación sensorial más directa del problema atmosférico: a) instrumentar un plan de emergencias en el cono plazo para enfrentar los momentos de crisis atmosférica; y b) instrumentar acciones que tiendan a evitar las condiciones de "mala calidad" del aire, y que reduzcan en $10 \%$ las "condiciones no satisfactorias". Las estrategias, como puede verse en el esquema (1), son en términos generales las que han persistido en los últimos programas. Las diferencias de los programas más recientes se centran, sobre todo, en sus intentos por tener un mayor control del cumplimiento de estas medidas, enfatizando la obligatoriedad y reafirmando su carácter coactivo. Quizá la diferencia esencial en el orden de prioridades del PCMCA respecto a los programas posteriores, es que éste pone un énfasis extraordinario en las acciones inmediatistas asociadas con las situaciones de emergencia; su finalidad es encarar los problemas que demandan inmediata solución y que preocupan baja la lógica de lo senserial a la opinión pública. Fuera de esta diferencia, la estrategia de 1979 establece ya con claridad la estructura programática que habrá de conducir los esfuerzos de ese programa y los de años posteriores: contaminación por vehículos automotores basada en la reformulación de los combustibles, dirigida a ejercer coacción absoluta sobre los consumidores de bienes y servicios (automovilistas), a plantear soluciones técnicas al problema del transporte, sobre todo dirigida a incrementar el número de unidades y a la apertura de nuevas rutas, y a evitar costos excesivos a los sectores productivos, en este caso a la industria automotriz o a los concesionarios del servicio de transporte.

2) Una política de control de la contaminación industrial sustentada también en una reformulación de los combustibles, lo cual se deja a la iniciativa del monopolio gubernamental representado por PEMEX, y una voluntad de mantener a la planta industrial al margen de costos excesivos. Las medidas de control se plantean hasta el punto en que no afecten la rentabilidad.

3) Medidas de control hacia fuentes naturales, las cuales no plantean ningún elemento realista de contención al crecimiento urbano, que no ofrece opciones de desarrollo agrícola para la región o que no percibe las diferencias de propuestas de reforestación y recuperación lacustre con los programas de pavimentación.

4) Medidas de apoyo en las que todas las propuestas que tienen que ver con la investigación, la educación o la participación ciudadana, se ligan a una percepción instrumental para los fines de legitimación de la acción gubernamental. (Por ejemplo, la participación ciudadana consiste en la apertura de una ventanilla de recepción de quejas.)

Ahora bien, como puede verse en el esquema, el marco institucional en el que se presenta este programa no puede ser más sintomático de su carácter voluntarista y de la superficialidad con la que se manejan las propuestas. Por un lado, las autoridades de la ciudad de México no contaban con una oficina para tratar los problemas ambientales, y la mayoría de los aspectos vinculados con la política del aire eran manejados por las autoridades sanitarias con jurisdicción nacional. Por otra parte, el PCMCA propone un arreglo institucional en el cual la política del aire aparece dictada y operada por una comisión intersecretarial con una amplia influencia formal en los distintos sectores de la administración pública vinculados al medio ambiente. No obstante, esta propuesta no deriva de una conceptuación de la contaminación y de lo ambiental que rescate su 
naturaleza compleja y que destaque las interrelaciones causales que la originan. El programa acierta al establecer, clasificar y distribuir acciones sectoriales concretas en tiempos definidos, aunque deja en suspenso el fundamento analítico de su propuesta institucional. En el plano operativo, no tiene control sobre sus propuestas de acción, tanto porque no les da obligatoriedad a sus medidas, como por no contar con mecanismos reales de vigilancia, de administración y de sanción. El arreglo institucional al que recurre el PCMCA no ha sido retomado en los programas posteriores, aun cuando en el diagnóstico de -estos últimos, los problemas ambientales son conceptuados en su carácter multicausal y con estrategias de acción que exigirían una estrategia multisectorial.

El PCMCA es indudablemente la apoteosis del voluntarismo, pero en ello sólo se distingue de los últimos programas por el grado extremo en el que esto se lleva a cabo: 1) no posee un diagnóstico que permita entender con claridad el tipo de construcción del problema ambiental que lleva a cabo; 2) no existe una explicación de los mecanismos lógicos y operativos que permita el paso del diagnóstico a las metas, y de éstas a las estrategias; 3) las metas en el corto, mediano y largo plazos no poseen relación lógica y operativa; 4) el arreglo institucional propuesto, como ya se mencionó, no corresponde al problema construido en el nivel del diagnóstico (no hay, por ejemplo, una calificación interdisciplinaria de lo ambiental que justifique el enfoque multisectorial con el que se pretende asignar tareas y emprender acciones en el plano programático); 5) no existe relación de congruencia entre elementos de diagnóstico, como es el caso de la evaluación del papel del problema del transporte y el tipo de medidas que se proponen para enfrentarlo (el transporte es calificado como un problema esencial en las emisiones de contaminantes, pero las medidas propuestas no se traducen en una restructuración del transporte de acuerdo con lo que exige el diagnóstico). Estos diversos problemas presentes en el programa le dan ese carácter voluntarista al que hago referencia.

Si midiéramos los éxitos o fracasos de un programa de esta naturaleza por el logro estricto de sus objetivos y metas, podríamos decir que el PCMCA resultó un completo fracaso. Primero, porque la contaminación atmosférica aumentó significativamente en los años posteriores a su implantación, llegando en 1987 a cerca de 5 millones de toneladas de emisiones anuales. Segundo, por la aparición o detección de altas concentraciones de ozono que, sistemáticamente, empezaron a violar los estándares. Y tercero, por la alta concen- tración de plomo, que apenas empieza a ser enfrentada con reformulaciones a las gasolinas a partir de 1986.

\section{b) Programa Integral Contra la Contaminación Atmosférica, 1990 (PICCA)}

El PICCA, presentado en 1990, constituye el primer esfuerzo sistemático para enfrentar el problema de la contaminación atmosférica en el valle de México. La diferencia fundamental respecto al anterior programa consiste en el mayor grado de conocimiento que muestra sobre la contaminación del aire, y en la calidad de la información en la que se sustentan sus propuestas. El PICCA responde a un momento distinto y a ello debe en parte la mayor seriedad con la que aborda el problema. Tiene como antecedente la crisis ambiental que se expresa en los años ochenta bajo la forma de inversiones térmicas, el disparamiento del problema del ozono, la irrupción en la escena pública del plomo venido a la atmósfera por las gasolinas (dado a conocer públicamente por los trabajos de investigación al respecto), el inicio sistemático de la medición y divulgación de los contaminantes criterios, así como la percepción de un agravamiento del problema atmosférico. Un conocimiento más completo de la problemática ambiental del valle de México por parte de la comunidad científica y el nacimiento de una conciencia ciudadana más interesada y preocupada por el deterioro ambiental, son elementos que combinados explican el empuje con el que la agenda gubernamental enfrenta el problema atmosférico ya desde mediados de los ochenta.

El PICCA refleja, de manera directa o indirecta, toda esta experiencia, llevando a cabo un diagnóstico más profesional, el cual se vale de la realización del primer inventario completo de emisiones para los llamados contaminantes criterio, en el cual se registran los volúmenes de sustancias emitidas a la atmósfera por parte de las actividades industriales y de servicios, del sector transporte y de fuentes naturales. Este programa recoge también algunas de las aportaciones de la comunidad científica sobre las causas y consecuencias de la contaminación del aire, con lo que se alcanza a percibir la gravedad del daño ambiental - sobre todo en términos de salud- para los habitantes del valle de México.

Los factores explicativos de la contaminación atmosférica propuestos por el PICCA muestran algunos cambios con respecto al programa de 1979, pero sobre todo destaca por la inclusión de 
algunos elementos con mayor alcance explicativo, como son los casos de los procesos industriales y sus sistemas de combustión, la importancia de las tecnologías anticontaminantes en industrias, servicios y transporte, y los efectos sinergéticos de los que participan las sustancias en la atmósfera, lo cual complica el análisis y redimensiona las consecuencias de la contaminación.

El PICCA construye el problema de la contaminación del aire asignando un peso significativo a elementos correspondientes tanto al nivel de análisis 1, como a los del nivel 2. En lo referente al nivel 1 , lo cual puede verse en el esquema 1 , alude a la contaminación como un problema derivado de las emisiones provenientes de procesos industriales, de servicios, y del uso intensivo de una flota vehicular con características muy específicas. La contaminación se explica fundamentalmente por la intensidad del consumo energético que tiene lugar en el valle de México. Según este programa, aun cuando los factores naturales son relevantes para explicar parte de la contaminación atmosférica, no son lo más característico de la región.

El PICCA, no obstante, se distingue sobre todo por la inclusión de factores explicativos que, en apariencia, pertenecen al nivel 2 de nuestro esquema analítico. A este nivel correspondería su explicación de la contaminación del aire como una consecuencia de procesos económicos y sociales entre los que destacan la intensidad en el uso de la energía en el transporte, la industria y los servicios; y los usos inadecuados del suelo, que repercuten en una mayor utilización del sistema de transporte al modificar tiempos y distancias de recorridos. La contaminación también es vista como resultado del proceso de industrialización y urbanización que arrancó a principios de los años cuarenta. Además, es percibida como una consecuencia no deseada en la búsqueda y obtención de mejores niveles de bienestar.

No obstante, esta noción de lo socioeconómico no alude estrictamente a relaciones sociales, enfatizando sobre todo los aspectos técnicos de la contaminación. Por ejemplo, la lógica del número le gana a la de lo social. En este programa, lo decisivo para explicar la contaminación es que la zona metropolitana de la ciudad de México (ZMCM) concentra la quinta parte de la población nacional, que genera $36 \%$ del producto interno bruto (PIB) y que consume $17 \%$ de la energía producida. Destacan también los 29.5 millones de viajes que allí tienen lugar, los 2.3 millones de autos privados que circulan en su territorio, y los paco más de 40 milestablecimientos industriales y de servicios que allí se asientan. Al PICCA le importa sobre todo el fenómeno de la concentración, ya sea de industrias, población o automotores. Le importan, por otro lado, los volúmenes consumidos de combustibles, no tanto su calidad y las características tecnológicas de los procesos de produccióno consumo a los que éstos se incorporan. La explicación sobre los usos del suelo, la distribución de las actividades humanas y el aumento en los tiempos y distancias recorridos por el sistema de transporte, constituyen ejemplos de una incapacidad para asociar los aspectos estrictamente técnicos a los de naturaleza social.

El crecimiento físico de la ciudad obedece a una dinámica social y económica determinada, que tiene que ver con el desarrollo de un tipo específico de actividades económicas y una dinámica poblacional dada; no obstante; el transporte como parte esencial del proceso de circulación delpersonas y productos que hace posible la realización de los sistemas de intercambios sociales, no puede ser considerado - e n el ámbito de las políticas públicas - únicamente como número de unidades, volúmenes combustibles consumidos, reparación de motores; etcétera, sino sobre todo como una organización que presta uñ servicio para el cual deben combinarse de manera adecuada das tipos de eficiencia, muchas veces contrapuestas: a) el traslado masivo de pasajeros cumpliendo requisitos básicos de efectividad y racionalidad, y b) realizar esta actividad manteniendo márgenes de rentabilidad que hagan de la prestación de este servicio algo atractivo para los inversionistas. $\mathrm{La}$ estructura de modos de transporte representa la verdadera fuerza a doblegar por el sistema de planeación, pero en muchos de sus aspectos decisivos está fuera del control de los planificadores. Por ejemplo, la relación entre la importancia del transporte público y el privado es decisiva en toda política que pretenda corregir los problemas de vialidad, contaminación, y transporte eficiente de personas; no obstante, esto obedece al desarrollo de tendencias económicas y sociales ligadas a la esencia misma de la sociedad industrial que se sale del margen de acción de los planificadores. Muy vinculado a esas tendencias se encuentra la distribución de la estructura modal: por ejemplo, el transporte eléctrico y el metro son opciones que parecen ideales desde el punto de vista de la eficiencia en el servicio, aunque no desde el punto de vista del beneficio económico. Pero al margen de estas características y tendencias, el transporte público es uno de esos espacios de actividad económica en los que el equilibrio entre la calidad y eficiencia del servicio y la lógica de la rentabilidad económica, debe ser sometido a una estricta regulación para que ninguno de sus dos componentes resulte afectado por cualquiera de ellos. En la ciudad de México, por ejemplo, el 
diseño de las rutas del servicio de transporte público ha sido primordialmente orientado por la lógica de la rentabilidad. Esto es evidente al analizar la autorización de rutas que obligan a los usuarios a tomar más líneas de transporte para llegar a sus lugares de destino. Una explicación del sistema de transporte público que no haga intervenir esta dimensión económica y que no la vincule a los agentes sociales y políticos en los que se expresa en términos reales, no es una explicación válida.

El PICCA cuenta con las condiciones para trascender el nivel explicativo 1 y pasar al 2 , pero no lo lleva a cabo. El inventario de emisiones del PICCA es un instrumento que brinda la posibilidad de asociar emisiones de sustancias con procesos y agentes económicos, lo que eventualmente permitiría pasar a la identificación de agentes sociales y políticos. Esto no lo lleva a cabo el PICCA en su diagnóstico, por lo que no lo puede incluir en sus propuestas de política., Tal procedimiento permitiría el paso del nivel explicativo 1 al 2. Este sólo en apariencia es de orden social, puesto que para serlo de manera real tendría que hacer intervenir a los agentes sociales mediante los cuales se transita, analíticamente, del nivel de explicaciones de naturaleza técnica, al de las de orden socioeconómico, y de allí al de las de tipo sociopolítico. Es esto lo que explica la limitación tecnicista de sus propuestas de acción, las cuales consisten en la introducción de filtros, convertidores, reformulación de combustibles, y sistemas de monitoreo, mientras que se dejan de lado las ideas de procesos y las condiciones de viabilidad económica y de factibilidad política de las propuestas.

El objetivo fundamental del PICCA es detener el crecimiento de la contaminación. Sus metas están claramente definidas en lo referente a la disminución del plomo, $\mathrm{SO}, \mathrm{NOx}, \mathrm{HC}$ y partículas, de tal manera que sea factible disminuir en un plazo de cinco años los más de 4 millones de toneladas de contaminantes vertidos anualmente a la atmósfera (tal y como lo registra el inventario de 1989), a 2.8 millones de toneladas. Analizado a la luz del inventario de 1994, este objetivo no se logró, aun cuando los volúmenes de algunos contaminantes descendieron.

La estrategia del PICCA para enfrentar el problema de la contaminación del aire es congruente con su construcción analítica del problema. La parte más significativa del programa está dirigida a la reformulación de los combustibles, a las medidas en materia de transporte, a lo que llama modernización tecnológica-productiva (que en términos reales no es sino el planteamiento de sustitución de combustibles en industria y servicios y algunas medidas complementarias). Pero la injerencia real y el verdadero margen de maniobra de los operadores de la política ambiental parecen tener lugar por el lado de los combustibles. Esto ha ocurrido así porque finalmente el monopolio de los combustibles en México está controlado por el Estado. No obstante, esto no significa la subordinación de la política energética a la política ambiental. En realidad en la práctica ocurre lo contrario; ha sido la política energética la que ha marcado el paso y la que ha tenido la capacidad de decidir el momento y el grado de su compromiso con la política ambiental. Las dos medidas restantes (la racionalización del transporte y la modernización de la tecnología productiva) son ámbitos en los que la acción gubernamental no ha tenido mayor influencia. Esto representa uno de los aspectos de la política ambiental en los que se expresan las limitaciones del diagnóstico tecnicista en el que se basa este programa. La restructuración del transporte es una restructuración de agentes. Esto adquiere mayor peso al constatarse que un nuevo trazado de rutas y una restructuración modal del transpone equivalen a medidas no sólo de naturaleza técnica, sino también económicas y políticas. Estos son los componentes de los programas de restructuración del sistema de transporte que los programas ambientales no han podido afectar a fondo. En el caso de la modernización tecnológica se expresan también estas fuerzas de naturaleza económica y política que resisten los contenidos normativos de los programas ambientales. Las propuestas de modernización no hacen referencia a ningún componente sustantivo en el plano de los procesos productivos, en el plano de la organización del trabajo, y en el de las relaciones insumo-producto que pudiera conducir a una modernización productiva con repercusiones en el plano de las descargas de contaminantes en la atmósfera. La estrategia en este rubro está concentrada en el control de emisiones y en la inspección industrial, en la sustitución de combustóleo, y en la proclamación de normas que prohíban la instalación de nuevas industrias contaminantes.

Los rubros complementarios de apoyo al PICCA, principalmente en cuanto a educación y participación ciudadana, carecen de un efecto real en el medio ambiente, sobre todo por no descansar en una estrategia vinculada a cada uno de los aspectos de la política $\mathrm{y}$, en el caso de la participación ciudadana, porque no propicia una participación en los distintos momentos de la planeación, limitándose a la recepción de quejas y recomendaciones de la ciudadanía. 
El PICCA cuenta para su operación con un aparato institucional del que no se disponía con anterioridad. A diferencia del programa de 1979, ya existe una estructura institucional en el gobierno de la ciudad de México ocupada directamente de los problemas ambientales, además de una ley que rige toda la actividad pública y privada en materia ambiental, llamada Ley General del Equilibrio y la Protección al Ambiente, de 1988. En el ámbito federal existen dentro de la Secretaría de Desarrollo Urbano y Ecología, el Instituto Nacional de Ecología (INE) y la Procuraduría Federal de Protección al Ambiente (PROFEPA), encargándose el primero de la normatividad ambiental, y la segunda, de la vigilancia del cumplimiento de esa normatividad. Además hay comisiones de ecología en la Cámara de Senadores, en la de Diputados y en la Asamblea de Representantes de la ciudad de México. El PICCA mismo fue elaborado por un Secretariado Técnico compuesto por diversas secretarías de Estado, el gobierno de la ciudad y el del Estado de México.

El PICCA muestra una congruencia entre la forma como define el problema y las estrategias que propone; ambas están ancladas en el nivel 1 del esquema de análisis aquí propuesto. Con todo, falla en tres aspectos cruciales: 1) No puede romper con la limitación tecnicista de su diagnóstico para apuntar a una estrategia que involucre la idea de procesos (productivos y sociales) y que haga intervenir los agentes sociales y políticos reales sobre los que descansan la mayor parte de las propuestas. 2) En la medida en que su diagnóstico se limita a una visión tecnicista y unilateral, en la cual las medidas relacionadas con el ámbito del consumo tienen mayor peso, no toma ventaja de la amplia estructura institucional de que dispone; sus propuestas sectoriales únicamente aluden a aquellos agentes directamente vinculados con algunos de los componentes técnicos del problema (CFE, PEMEX, SEDUE, DDF, etcétera). 3) Vinculadas con las anteriores fallas, ante la ausencia de una conceptuación comprensiva del problema en la que intervinieran elementos de los niveles 1 y 2 jerarquizados con una lógica analítica, se realiza una asignación de funciones y acciones a la estructura institucional de los distintos niveles de gobierno involucrados, que no da cuenta de la complejidad del problema ambiental y que no toma provecho del carácter multisectorial de las instituciones formalmente participantes en la política del aire.

No existe, por otra parte, esfuerzo alguno por analizar y evaluar la viabilidad de la estructura institucional, las prácticas reales -no las formales de estas instituciones-, los márgenes de maniobra de las oficinas del medio ambiente, los agentes económicos, políticos y sociales comprometidos en la dinámica ambiental y su respuesta potencial ante medidas que implican una redistribución general de los costos sociales del deterioro ambiental.

Una propuesta de política debe apoyarse en un principio de realidad básico para lograr el salto del voluntarismo al manejo de factores y actores concretos. El PICCA, por ejemplo, planteó entre sus medidas la urgencia de que 1,550 industrias, de acuerdo a como lo "permitan sus recursos y posibilidades, pero no mayor a 36 meses a partir del 15 de noviembre de 1990", sustituyeran procesos contaminantes o instalaran equipos de control. En materia de transporte propuso fomentar el colectivo por sobre el individual, sobre todo fortaleciendo al metro como eje de esta propuesta. A la industria petrolera se le exigieron mejores combustibles y control sobre sus emisiones.

No obstante, no brinda elementos para evaluar la viabilidad de sus propuestas, esto es, las condiciones bajo las cuales se pondrán en práctica estas medidas. ¿Cuál es la capacidad real de las instituciones ambientales para imponer el interés ambiental colectivo por sobre el de sus distiatos agentes? ¿Es posible, sin llegar al cierre de industrias, alcanzar estas metas? Esto significa no la potencialidad de emprender medidas de cierre, sino la capacidad real para mantener en funcionamiento la planta productiva, confrontar y negociar con agentes en algunos casos con gran peso económico y político, y lograr metas ambientales concretas.

En el caso de la industria petrolera, jes posible controlar la calidad de los combustibles, e imponer una medida restrictiva de fondo a esta industria?, ¿cuál es el mejor camino en el caso de industrias con fuerte presencia económica y gran influencia política? y ¿cómo dosificar la coacción con la negociación y conciliación? Estos son los casos de industrias tales como la metalmecánica, la química, la automotriz y la cementera.

\section{c) Programa para Mejorar la Calidad del Aire en el Valle de México, 1995-2000 (PROAIRE)}

Este programa, que fue presentado públicamente en 1996, presenta un panorama más comprensivo sobre los factores que provocan la contaminación del aire. El problema ya no se reduce únicamente a los volúmenes de contaminantes vertidos en la atmósfera, ni a la concentración de actividades económicas y humanas en general en 
el valle de México, sino que se habla del comportamiento físicoquímico de los contaminantes, de la dinámica meteorológica, de la estructura y los procesos urbanos, de pautas de consumo y agentes sociales. Sería muy difícil encontrar faltantes en esta colección de factores intervinientes. Clasificando conforme a nuestro esquema los distintos factores que PROAIRE hace intervenir, tendríamos ubicados en el nivel 1 las emisiones en la atmósfera del valle de México emitidas actualmente y en el pasado bajo las condiciones atmosféricas vigentes en la región, el consumo energético, la calidad de los combustibles, la tecnología existente para control de emisiones, la tecnología existente en procesos productivos, de servicios y transporte; la estructura modal del transporte, los tiempos y distancia recorridos, vialidad, etcétera. En el nivel 2 se ubica un número significativo de factores, como es el caso de la alusión a procesos económicos, sociales y culturales. Los procesos que tienen lugar en la ciudad son considerados como fundamentales para dar cuenta de los problemas ambientales, particularmente para explicar el problema atmosférico.

No obstante, la inclusión de una dimensión social en la construcción del problema ambiental por parte de PROAIRE, no resulta útil para explicar los procesos dado que éstos sólo son mencionados con fines discursivos, con el propósito de añadir factores, no de explicar los fenómenos. Por ejemplo, la alusión a un enfoque sistémico supondría una voluntad de vincular los factores de nivel 1 con los de nivel 2; no obstante, tales factores únicamente aparecen sobrepuestos. Por otra parte, se hace alusión a agentes sociales, pero éstos aparecen analizados desde la óptica del consumo, por lo tanto, son presentados en lo que tienen en común, esto es, usuarios de bienes y servicios, por lo tanto, como igualmente culpables y responsables del deterioro ambiental; no se muestran en sus diferencias, como portadores de recursos diferenciables, ubicados en una estructura de relaciones jerárquicas y en el marco de relaciones de poder. La ciudad de PROAIRE está despersonificada, con agentes socialmente indiferenciados y políticamente neutros. La idea de lo socioeconómico que se incluye funciona con la lógica de los grandes agregados; cuentan no como agentes reales, sino como causa y consecuencias que derivan de grandes agregados como la producción, el consumo, el transporte, la cultura, etcétera.

Pasando al aspecto programático, destaca el hecho de que aun cuando el diagnóstico haga intervenir un número considerable de factores, la estrategia es muy similar a las de los programas de 1979 y 1990. Respecto a éstos únicamente se distingue por la consideración, en el plano estratégico, de la idea de integración de políticas de desarrollo urbano, transporte y medio ambiente, y una mayor especificación en la estrategia de incentivos económicos. El resto de las medidas (mejores tecnologías y energéticos en industria, servicios y automotores; mayor y mejor oferta de transporte; vigilancia e inspección vehicular e industrial y de servicios más estricta y más amplia; información, educación y participación ciudadana) no hacen sino llevar a un grado de mayor profundidad las propuestas ya incluidas en el programa de 1979.

El marco institucional de PROAIRE se caracteriza por el hecho de que además de contar con la estructura institucional del PICCA, cuenta con el gran paraguas formado por la Secretaría del Medio Ambiente, Recursos Naturales y Pesca (SEMARNAP), de carácter federal, y la Secretaría del Medio Ambiente del gobierno de la ciudad de México; ambas creadas a fines de 1994, al inicio de la administración 1994-2000. Cuenta también con dependencias ambientales en el Estado de México. Este programa surge bajo una noción de la concertación de agentes sociales que pretende establecer compromisos entre diversos agentes tanto gubernamentales como académicos y no gubernamentales, con lo cual explora con un ámbito de las políticas públicas novedoso en el contexto mexicano.

Estos son algunos de los rasgos del diagnóstico y de las propuestas programáticas de PROAIRE; no obstante, en el plano de la congruencia entre diagnósticos y estrategias existen algunas inconsistencias que vale la pena destacar. No hay una correspondencia entre el carácter sistémico con que se califica a los factores que provocan los problemas atmosféricos y la estrategia de acción; no hay, por ejemplo, una propuesta de paquetes de política que incluya, de manera sistemática y de procesos, a los diversos sectores de la administración y a los diversos agentes intervinientes. No hay una propuesta integral del problema del aire ubicándolo en el contexto de los otros problemas ambientales. Los factores se suman unos a otros; no existe un esfuerzo por encontrar secuencias analíticas entre emisiones, procesos económicos y procesos urbanos. Las medidas tomadas para tratar el predominio del auto privado y sus efectos en el medio ambiente, se quedan cortas en relación con el diagnóstico que lo ubica como el principal depredador urbano.

No hay correspondencia entre las interrelaciones establecidas en el diagnóstico y el plano de las propuestas. Estas últimas se confinan a los aspectos más técnicos del nivel 1 y no se consideran estrategias para el nivel 2. 
Visto en su conjunto, el documento no logra construir un marco conceptual unitario; más bien presenta una superposición de distintos discursos ambientalistas y ecológicos con fines retóricos más que analíticos. No existe una articulación analítica entre los componentesquímicos, físicos, ecológicos, económicos, sociológicos y políticos del marco conceptual. El carácter sistémico e interdisciplinario al que alude el programa para pensar lo ambiental, es sólo un recurso discursivo, no un elemento de reflexión. Cada uno de estos recortes analíticos aparece en su carácter autosuficiente y autoexplicativo.

Esto sucede en el caso del marco conceptual, incluido en el capítulo VI, en el que la forma discursiva aparece como un simple fluir del deseo:

En primer lugar, es insoslayable la función de una multiplicidad de conceptos que actualmente se encuentran dispersos, principalmente en los ámbitos de las ciencias ambientales y de la economía. Ello requiere empezar por una actitud abierta al cambio, dejando de lado prejuicios hoy día altamente generalizados respecto al tipo $y$ al alcance de las medidas aplicables Ś́lo aś se podrá tener éxito en la introducción y en

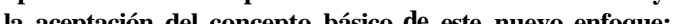
desarrollo urbano sustentable (DDF et al., 1996:117)

Puede decirse, primeramente, que el desarrollo urbano sustentable así planteado es una frase vacía, puesto que no alude a ningún contenido específico, recurriendo más bien a la aceptación social lograda por un par de palabras: desarrollo y sustentabilidad. En segundolugar, no es función de una política promover la aceptación de términos o conceptos, sino movilizar fuerzas sociales y políticas para obtener resultados viables en aquellos sistemas de prácticas que se desea afectar. En tercer lugar, olvidar prejuicios y la mencionada apertura hacia el cambio no reflejan las condiciones reales requeridas para la viabilidad de una política; esto únicamente da cuenta de un deseo o, a lo sumo, una voluntad.

En PROAIRE los procesos urbanos y la política urbana son esenciales para llevar a cabo con éxito una política ambiental. No obstante, la idea de ciudad de PROAIRE no sólo es parcial e irrelevante para dar cuenta de los procesos que allí tienen lugar, sino que retrocede en al menos 70 años en la interpretación de la dinámica urbana. La escuela ecologista clásica de Chicago que analizó, en la década de los veinte, los problemas urbanos recurriendo a un modelo ecológico de corte biologicista, tenía finalmente una noción más realista que la que se maneja en el documento que aquí se comenta. Para dicha escuela de pensamiento, el orden urbano era la consecuencia de la lucha competitiva de distintos agentes que se disputaban los recursos de la ciudad. La ocupación del espacio - con el consecuente orden urbano así generado- venía a expresar el balance de estas fuerzas que se contraponían y que daban lugar a un orden desigual procedente de la confrontación de fuerzas de naturaleza opuesta.

La ciudad de PROAIRE no conoce los antagonismos ni sospecha el conflicto: "La ciudad es hoy en día la forma más compleja y acabada de organización humana. En ella podemos convivir millones de seres vivos (incluidas la fauna y la flora urbana), realizar simultáneamente un número incontable de actividades cotidianas, interactuar, comunicarnos, producir y consumir bienes y servicios, todo sin que la ciudad se colapse; el fenómeno urbano si bien complejo y multidimensional, es algo que funciona" (DDF et al., 1996:120). Vista bajo esta perspectiva, la ciudad aparece como un agregado de acciones y reacciones en las que indiscriminadamente se mezclan hombres, territorios, seres vivos, y hechos, en un contexto social neutro.

Es importante subrayar las consecuencias en términos de planteamientos de política, de ese tono neutro, de esa falta de agentes sociales y políticos reales, esa ausencia de conflicto y la no mención al carácter desigual de la apropiación de los recursos urbanos y del consumo, que constituyen la idea de ciudad de PROAIRE. Es por ello que muchas de sus propuestas adquieren un carácter voluntarista, cuyo fundamento es la manipulación de recursos tecnológicos y la constante alusión a lo científico, todo ello descontextualizado de una organización social real. El esquema 1, en el cual se sintetiza la concepción del problema atmosférico, lo mismo que el 4, en el cual se exponen resumidamente las metas y estrategias, no logran situar el problema ambiental en el contexto social en el que tiene lugar.

Los factores de la contaminación y las estrategias apuntan también al privilegio de soluciones tecnológicas, al énfasis en el consumo por sobre la producción de los bienes y servicios. El propósito es disminuir las emisiones contaminantes con el recurso del convertidor catalítico y de la introducción de filtros, pero sin el análisis de los procesos técnicos, organizativos y logísticos de la producción y del consumo mismos. No hay un cuestionamiento a la lógica y racionalidad productivas, pero sí una al patrón de consumo. En esto es similar al PCMCA y al PICCA. 
Así como el diagnóstico no alude a agentes, instituciones, ni a procesos en los cuales toman forma o personifican los problemas ambientales, las estrategias y propuestas de acción abstraen a los agentes sociales a quienes van dirigidas las medidas, desconociendo o desestimando sus acciones y reacciones en los ámbitos económico, social y político. Esto constituye una política de naturaleza voluntarista porque no alude al terreno real en el que sus actores viven, actúan, negocian, acuerdan o se oponen respecto a las leyes, normas y mandatos mediante los cuales se les asignan costos y se les pretende inducir a un nuevo arreglo en materia de la distribución social de estos costos.

La ausencia de las variables sociopolíticas fundamentales en todo proceso de elaboración e implantación de las políticas públicas, conduce al olvido o desconocimiento de que la aplicación de toda norma presupone: 1) una negociación sectorial previa a su promulgación; 2) la constitución de un escenario real para su cumplimiento; 3) la existencia, por parte del emisor y del receptor, de la norma de una voluntad de cumplimiento; 4) una capacidad y voluntad de sanción por parte de la autoridad; y 5) una capacidad real de las partes (emisor-receptor de la norma) para negociar la aplicación de la norma.

Todos estos elementos dan cuenta de las muchas mediaciones que existen entre la promulgación de la norma y su impacto real y concreto en la disminución de la contaminación atmosférica. La consideración o no de estos elementos decide el carácter voluntarista o realista de las propuestas de políticas y programas en materia ambiental.

El programa PROAIRE plantea la salida tecnológica como sustento esencial de la política del aire y hace descansar toda propuesta de sustentabilidad urbana en la superación de la condición de pobreza por la vía del incremento de la productividad: “[...] poco o nada se puede hacer en la indigencia o ante los apremios, mientras que en la pobreza, las prioridades y las expectativas sociales se vuelcan al corto plazo, prevaleciendo tasas de descuento relativamente altas en la estructura de preferencias, lo que invalida y descarta los proyectos a futuro como los de sustentabilidad ambiental" (DDF et al., 1996:123). El supuesto de esta afirmación es que la superación de la pobreza es posible con el aumento de la productividad. Esta concepción oculta el papel central de la distribución de la riqueza en el origen de la pobreza. Por el lado de la cuestión ambiental, esta tesis se presenta de manera sutil en aquellas interpretaciones y propuestas que plantean la no satisfacción de las necesidades humanas debido a la existencia de una escasez natural de recursos que impide su reparto social equitativo. En este caso también, el problema de la distribución desigual de los recursos es esencial para entender la verdadera esencia de la escasez; se hablaría entonces, más que de una escasez natural, de una de carácter social: la que deriva de la desigual distribución de recursos.

La forma de construir el problema ambiental es fundamental en el planteamiento de las propuestas de política y en las estrategias de acción para enfrentar la contaminación. Si el problema del aire, dei agua y de la calidad general del medio ambiente, es percibido como un problema de escasez o determinado por fuerzas naturales, entonces las propuestas de política pondrán énfasis en las soluciones tecnológicas, planteándose un análisis social en el que la sociedad aparezca como resultado de la libre concurrencia de acciones y voluntades individuales que, con una participación similar, crean resultados comunes o dan lugar a resultados no siempre deseables.

Por el contrario, si los problemas ambientales no son vistos únicamente bajo sus aspectos naturales, entonces las propuestas y estrategias deberán de incorporar la dimensión social y política. En este caso es necesario explicar las condiciones sociales de la creación de la escasez, o las condiciones sociales que originan el deterioro ambiental. Esto lleva al análisis de la vida social como producto de la confrontación, del conflicto; de la búsqueda del consenso entre agentes que no sólo no son funcionalmente iguales, sino que ocupan posiciones distintas en una estructura social jerárquica. Las propuestas de política y las estrategias deben considerar soluciones en el ámbito de lo ambiental, en el de lo económico, en el de lo tecnológico y en el de lo sociopolítico. En este último, el problema de la distribución de los costos de la reparación del daño ambiental debe ser considerado como un elemento decisivo en una propuesta objetiva y realista.

Una propuesta de política pública, como es el caso de la del aire, debe prever las condiciones de aplicación de sus propuestas, y tener claridad sobre los límites de la acción reguladora. Estos límites están acotados por el modelo de desarrollo y su capacidad de asimilación y cambio, por la voluntad social de llegar en materia ambiental hasta el punto en que el valor del medio ambiente y su carácter de parte integrante del paquete del bienestar, no se contrapongan o no devengan menos esenciales con valores o necesidades concebidas por el grupo (social) como de naturaleza más esencial. El otro límite decisivo es el que demarcan los propios actores de acuerdo con la capacidad que poseen para manejar 
recursos económicos, ideológicos y políticos, y los acuerdos y saldos derivados de la confrontación de estas posiciones en un momento dado en el tiempo.

Refiriéndonos a estos actores, debe incluirse en el análisis el poder de negociación muy elevado que poseen algunos de ellos y su inclusión como elemento de viabilidad de las propuestas. La política ambiental, lo mismo que toda política pública, tiene un componente coercitivo y uno de búsqueda de consenso. La aplicación de una política ambiental efectiva consiste en el manejo adecuado, oportuno y eficaz de ambos componentes en un contexto en el que los componentes físico-químico-meteorológicos que integran el problema ambiental en su dimensión "física" (nivel 1), sus componentes de procesos económicos y tecnológicos y sus aspectos sociopolíticos (nivel 2), sean evaluados, ponderados y ubicados en su justa dimensión. Hablo de una política pública voluntarista o retórica, cuando estos elementos no son incluidos en sus marcos conceptuales y en sus propuestas de acción. (Ver cuadros en el anexo).

Conclusiones: elementos para un esquema ideal de construcción del problema atmosférico

Por Último y sintetizando la crítica a la construcción gubernamental de la contaminación atmosférica, quiero comparar esta construcción con una de naturaleza ideal, en la cual la contaminación del aire en términos de sus características y composición serían pensadas como una consecuencia de fenómenos naturales, sociales y políticos de mayor alcance explicativo, y con una jerarquización distinta a aquella expuesta por los programas gubernamentales. Las implicaciones para la práctica de la programación de una concepción de esta naturaleza, serían el planteamiento de propuestas programáticas dirigidas hacia los distintos niveles de existencia de los problemas ambientales, así como una jerarquización de las acciones que permitiría enfrentar simultáneamente problemas coyunturales y estructurales, estableciendo prioridades dentro de esa dinámica que surge del tratamiento de problemas emergentes, por un lado, y de problemas de fondo, por otro (véase esquema 5 en el anexo).

Los tres programas exploran, con relativo éxito, ese nivel físico-químico-técnico(nivel 1) de la contaminación. Los tres señalan la presencia de componentes sociales entre las causas que originan los problemas (nivel 2). No obstante, para el primer y segundo programas lo social se agota en el fenómeno de la concentración de actividades económicas (industria, servicios, número de autos, etcétera) y de población. El tercer programa incluye, como elemento de diagnóstico, un listado de otros componentes más cualitativos, que intervienen como elementos explicativos; tales son los casos de los factores culturales y la idea de procesos urbanos. No obstante, estos elementos entran al marco conceptual más como componentes decorativos que con una finalidad explicativa, puesto que no se interrelacionan entre ellos y, por otra parte, no son incorporados en las propuestas de acción. PROAIRE hace intervenir más variables y algunas de ellas tendrían un alto poder explicativo, si bien no se hallan jerarquizadas en el plano del diagnóstico y no forman parte de un marco interpretativo unitario. En el plano de las propuestas de acción, no hay congruencia entre marco conceptual y estrategias. La política del aire (tal y como la entiendo en el esquema que presento) debe ser construida con base en dos componentes:

1) Una conceptuación que ubique el problema atmosférico en sus distintos niveles de existencia: a) como parte de una problemática ambiental con la que interactúa; b) como producto de características geográficas y naturales; c) como consecuencia de una tecnología y de formas organizativasen el plano de las actividades económicas; $d$ ) como resultado de juegos de fuerzas económicas, sociales y políticas; y e) como fenómeno influido, en el plano macro, por un orden urbano y un orden social, en el cual coinciden un sistema de valores y un orden económico y político que le asigna sus verdaderos contenidos a la sociedad en su conjunto.

El segundo componente en el que debe sustentarse la política del aire tiene que ver con la estrategia específica de acción, lo cual incluye los objetivos, metas, estrategias, y el marco institucional en el que se desarrollará la propuesta. Lo central de este aspecto es la necesidad de establecer congruencia entre la construcción del problema en términos del diagnóstico y el tipo de propuestas concretas contenidas en los programas. 
Deben tenerse en cuenta los aspectos básicos de esta crítica. Uno de ellos atañe a la construcción del problema de la contaminación atmosférica efectuada en los programas gubernamentales, particularmente lo relacionado con su conceptuación. En este caso mis observaciones van dirigidas a la capacidad o incapacidad de los diagnósticos y de los marcos conceptuales para pensar un problema multicausal en sus distintos niveles de existencia, jerarquizando éstos de acuerdo con los propósitos de dichos diagnósticos. Cuando el propósito es el diseño de una política pública, el marco conceptual debe hacer intervenir a los agentes en los cuales se personifican los aspectos físicos, técnicos, tecnológicos, económicos, etcétera, de los problemas ambientales; a las relaciones entre productores y consumidores en un orden social determinado; al sistema de valores en el cual norman sus vidas los agentes; y a los intercambios políticos de que participan.

El otro aspecto básico de mi crítica apunta hacia la necesaria congruencia que debe existir entre la construcción del problema en el sector gubernamental, y la estrategia de acción propuesta para enfrentar los problemas. En este sentido, resulta inconveniente tanto un programa que define de manera simplista el problema de la contaminación pero que plantea soluciones complejas, como aquel que define de manera compleja el problema y plantea soluciones de manera simplista. El primer caso se aplica al PCMCA y el segundo a PROAIRE.

Con el esquema que presento se podría intervenir analítica y programáticamente en el problema de la contaminación atmosférica. En el esquema, el problema del aire aparece visto desde estas dos intervenciones. Así, desde el punto de vista analítico, la contaminación aparece como un producto combinado de factores físico-técnicos, económicos, sociales y culturales. Entre lo físicotécnico y lo socio-cultural existe un mayor grado de eficacia explicativa en favor de este último en la medida en que la organización social y la acción misma del hombre son elementos modificadores esenciales del medio ambiente natural. En este mismo nivel analítico, el modelo aquí presentado hace intervenir a los agentes económicos y políticos que se derivan o que están involucrados en problemas ambientales como el de la contaminación. Son estos agentes los receptores y las fuerzas reales que participan de las políticas, y finalmente son ellos mismos quienes deciden, con el control de recursos que ejercen y con sus acciones y reacciones en un escenario signado por la disputa y la negociación, el tipo de política puesta en práctica por la autoridad gubernamental.

Desde el punto de vista de la segunda intervención en el problema de la contaminación, esto es, la intervención programática, la política del aire aparece en el esquema presentado requiriendo estrategias en los distintos niveles de existencia del problema ambiental. A continuación, el esquema alude a la necesidad de diseñar un sistema de planeación para los propósitos de la política del aire en el cual se ubica a esta política de manera jerárquica, de acuerdo con su grado de eficacia y sus márgenes de maniobra, en el contexto de otras políticas sectoriales con las que compite por recursos y por costos. Conforme al esquema, la política económica posee un mayor margen de maniobra y ejerce un control de recursos más significativos, conteniendo por lo tanto a la ambiental y a la del aire. No considerar esta jerarquía entre las distintas políticas públicas, lleva a las autoridades ambientales a sobrevalorar o a subestimar el ámbito específico y el alcance de la política ambiental. La propuesta de acción que derivaría de una concepción del problema ambiental multicausal es una que asigna, también diferencialmente, responsabilidades a los distintos sectores y agentes involucrados. Es esto lo que se indica en el último cuadro del esquema, en el que destaca la necesidad de: 1) congruencia entre diagnóstico y estrategia; 2) la inclusión de los distintos agentes de acuerdo con su importancia en el origen y solución de los problemas; 3) la jerarquización de las acciones en relación con el grado de efectividad para encarar los problemas y la dinámica entre problemas coyunturales y de fondo; y 4) identificación y, en su caso, creación de márgenes de maniobra para la acción sectorial y de los agentes. 
A N E X O

Cuadro 1

Número de días con lecturas IMECA superiores a los 100, 200 , 250 y 300 puntos (1988-1996) (Ozono)

\begin{tabular}{|c|c|c|c|c|}
\hline Año & Mayor que 100 & Mayor que 200 & Mayor que 250 & $\begin{array}{c}\text { Mayor que } \\
300\end{array}$ \\
\hline 1988 & 329 & 67 & 11 & 1 \\
\hline 1989 & 329 & 15 & 3 & 0 \\
\hline 1990 & 328 & 84 & 27 & 3 \\
\hline 1991 & 353 & 173 & 56 & 8 \\
\hline 1992 & 333 & 123 & 37 & 11 \\
\hline 1993 & 324 & 80 & 14 & 1 \\
\hline 1994 & 344 & 93 & 4 & 0 \\
\hline 1995 & 324 & 88 & 6 & 0 \\
\hline 1996 & 327 & 69 & 5 & 0 \\
\hline Promedio & 332 & 88 & 18 & 3 \\
\hline Valor mínimo & 324 & 15 & 3 & 0 \\
\hline Valor máximo & 353 & 173 & 56 & 11 \\
\hline
\end{tabular}

Fuente: DDF, 1996 y Red Automática de Monitoreo Atmosférico. Datos para 1996.

Cuadro 2

Inventario de emisiones para el valle de México, 1985

\begin{tabular}{|l|c|c|c|c|c|c|}
\hline & PST & $\mathrm{SO}_{2}$ & NOx & $\mathrm{CO}$ & $\mathrm{HC}$ & Total \\
\hline $\begin{array}{l}\text { Fuentes } \\
\text { fijas }\end{array}$ & $2.55 \%$ & $8.70 \%$ & $1.95 \%$ & $1.05 \%$ & $0.75 \%$ & $15.00 \%$ \\
\hline $\begin{array}{l}\text { Fuentes } \\
\text { móviles }\end{array}$ & - & $1.60 \%$ & $1.04 \%$ & $71.20 \%$ & $7.52 \%$ & $80.00 \%$ \\
\hline $\begin{array}{l}\text { Fuentes } \\
\text { naturales }\end{array}$ & $5.00 \%$ & - & - & - & - & $5.00 \%$ \\
\hline Total & $7.55 \%$ & $10.30 \%$ & $2.99 \%$ & $72.25 \%$ & $8.27 \%$ & $100.00 \%$ \\
\hline
\end{tabular}

Fuente: Informe sobre la situación del Medio Ambiente para México, SEDUE, 1986.
Cuadro 3

Inventario de emisiones para el valle de México, 1987

\begin{tabular}{|l|c|c|c|c|c|c|}
\hline & PST & SO, & NOx & CO & HC & Total \\
\hline $\begin{array}{l}\text { Fuentes } \\
\text { fijas }\end{array}$ & $2.67 \%$ & $4.93 \%$ & $1.42 \%$ & $1.11 \%$ & $2.87 \%$ & $13.00 \%$ \\
\hline $\begin{array}{l}\text { Fuentes } \\
\text { móviles }\end{array}$ & $0.84 \%$ & $0.15 \%$ & $2.26 \%$ & $72.47 \%$ & $6.28 \%$ & $82.00 \%$ \\
\hline $\begin{array}{l}\text { Fuentes } \\
\text { naturales }\end{array}$ & $5.00 \%$ & & & & & $5.00 \%$ \\
\hline Total & $8.51 \%$ & $5.08 \%$ & $3.68 \%$ & $73.58 \%$ & $9.16 \%$ & $100.00 \%$ \\
\hline
\end{tabular}

Fuente: SEDUE, 1988. Citado en Fundación Universo Veintiuno,Desarrallo y Medio Ambiente en México. Diagnóstico, Fundación Universo Veintiuno, 1990.

PST $=$ Partículas suspendidas totales

$\mathrm{SO}_{2}=$ Bióxido de azufre

$\mathrm{CO}=$ Monóxido de nitrógeno

$\mathrm{NO}=$ Óxidos de nitrógeno

$\mathrm{HC}=$ Hidrocarburos 
Cuadro 4

Inventarios de emisiones para el valle de México, 1989-1994

Inventarios de emisiones 1989() - 1994()

\begin{tabular}{|c|c|c|c|c|c|c|c|c|c|c|c|c|}
\hline \multirow[t]{3}{*}{ Fuente } & \multicolumn{12}{|c|}{ Tipo de contaminante (ton/akio) } \\
\hline & \multicolumn{2}{|c|}{ PST } & \multicolumn{2}{|c|}{$\mathrm{SO}_{2}$} & \multicolumn{2}{|c|}{ co } & \multicolumn{2}{|c|}{ NOx } & \multicolumn{2}{|c|}{$\mathrm{HC}$} & \multicolumn{2}{|c|}{ Total } \\
\hline & 1989 & 1994 & 1989 & 1994 & 1989 & 1994 & 1989 & 1994 & 1989 & 1994 & 1989 & 1994 \\
\hline Energia & $4,699.00$ & 169.56 & $73,028.00$ & 104.28 & $53,205.00$ & $1,295.76$ & $9,846.00$ & $17,883,36$ & $31,843.00$ & 254.86 & $172,621.00$ & $19,707.84$ \\
\hline Industria & $10,242.00$ & $6,188.16$ & $65,732.00$ & $25,947.12$ & $15,816.00$ & $3,400.22$ & $28,883.00$ & $13,636,56$ & $39,981.00$ & $33,098.77$ & $160,654.00$ & $86,270.89$ \\
\hline Servicios & $2,469.00$ & $1,076.77$ & $22,060.00$ & $7,216.83$ & 466.00 & 948.13 & $3,988.00$ & $5,338.92$ & 121.00 & $398,178.23$ & $29,104.00$ & $412,758.88$ \\
\hline Transporte & 9,549.00 & $18,842.00$ & $44,774.0 \mathrm{q}$ & $12,200.00$ & $2,853,778.00$ & $2,348,497.00$ & $133,691.00$ & $91,787,00$ & $300,380.00$ & $555,319.00$ & $3,342 \quad 172.00$ & $3,026,645.20$ \\
\hline Degradedéón ecolobgias & $423,640.00$ & $425,337.00$ & 131.09 & 0.09 & $27,362.00$ & 0.00 & 931.00 & 0.00 & $199,776.00$ & $38,909.00$ & $651,840.00$ & $464,246.00$ \\
\hline Total & $450,599.00$ & $451,613,49$ & $205,725.00$ & $45,468.00$ & $2,950,627.00$ & $2,358,141.34$ & $177,339.00$ & $128,646.00$ & $572,101.00$ & $1,023,760.00$ & $4,356,391.00$ & $4,009,629.00$ \\
\hline
\end{tabular}

Inventarios de emisiones $1989\left(^{(\mathfrak{l})}-19940\right.$

Porcentajes en peso por contaminante

\begin{tabular}{|c|c|c|c|c|c|c|c|c|c|c|c|c|}
\hline \multirow[t]{3}{*}{ Fuente } & \multicolumn{12}{|c|}{ Tipo de contaminante (porcentajes en peso por contaminante) } \\
\hline & \multicolumn{2}{|c|}{ PST } & \multicolumn{2}{|c|}{ so, } & \multicolumn{2}{|c|}{ co } & \multicolumn{2}{|c|}{ NOx } & \multicolumn{2}{|c|}{ HC } & \multicolumn{2}{|c|}{ Total } \\
\hline & 1989 & 1994 & 1989 & 1994 & 1989 & 1994 & 1989 & 1994 & 1989 & 1994 & 1989 & 1994 \\
\hline Energia & $1.00 \%$ & $0.00 \% 9$ & $35.50 \% \mathrm{~m}$ & $0.00 \% \mathrm{~m}$ & $1.80 \% \mathrm{a}$ & $0.05 \%$ & $5.60 \times 4$ & $13.900 \%$ & $5.60 \times$ & $0.02 \%$ & $4.00 \%$ & $0.50 \%$ \\
\hline Industria & $2.000 \times$ & $1.37 \%$ & $32.00 \% 4$ & $57.00 \%$ & $0.50 \% \%$ & $0.35 \times 4$ & $16.300 \%$ & $10.609 \%$ & 7,000 & $3.2396 \mathrm{f}$ & $3.70 \%$ & $2.20 \%$ \\
\hline Servictos & $1.00 \% \mathrm{~d}$ & $0.24 \% 6$ & $10.70 \%$ & 16.0005 & $0.00 \%$ & 0.000 & $2.20 \%$ & $4.20 \% 4$ & $0,000 \times$ & $38.22 \times 6$ & $0.70 \% \mathrm{q}$ & $10.30 \%$ \\
\hline Transporte & 2.0004 & $4.17 \times 6$ & $21.800 \%$ & $27.00 \%$ & 96.7004 & $99.500 \times 4$ & $75.40 \%$ & $71.30 \%$ & $32,30 \%$ & $94.14 \times 4$ & 76.70\% & $73.50 \%$ \\
\hline Degradedín ecolbgefien & $94.00 \%$ & 94.18\% & $0.100 \mathrm{a}$ & $0.00 \%$ & $0.90 \times 4$ & $0.000 \times 4$ & $0.30 \times 6$ & 0.0004 & $34900 \times 1$ & 3.7996 & $15.00 \%$ & $11.60 \%$ \\
\hline Total & $100 \%$ & $100 \%$ & $100 \%$ & $100 \%$ & $100 \%$ & $1000 \times$ & $100 \%$ & $100 \%$ & 10004 & $100 \%$ & $1000 \times$ & $100 \%$ \\
\hline 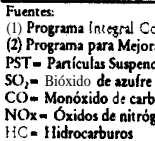 & & & & & DDI & & & & & & & \\
\hline
\end{tabular}

Cuadro 5

Inventario de emisiones del sector transporte para el valle de México, 1989-1994

Inventarios de emisiones $1989\left(^{(}\right)-1994\left(^{(}\right)$

\begin{tabular}{|c|c|c|c|c|c|c|c|c|c|c|c|c|}
\hline \multirow[t]{3}{*}{ Tipo de fuente } & \multicolumn{12}{|c|}{ Tipo de contaminante (ton/año) } \\
\hline & \multicolumn{2}{|c|}{ PST } & \multicolumn{2}{|c|}{$\mathrm{SO}_{2}$} & \multicolumn{2}{|c|}{$\mathrm{co}$} & \multicolumn{2}{|c|}{ NOx } & \multicolumn{2}{|c|}{$\mathrm{HC}$} & \multicolumn{2}{|c|}{ Total } \\
\hline & 1989 & 1994 & 1989 & 1994 & 1989 & 1994 & 1989 & 1994 & 1989 & 1994 & 1989 & 1994 \\
\hline Auto particular & 4.398 .09 & $10,321.00$ & $3,557.09$ & $6,061.50$ & $1,328,133.00$ & $1,044,008.00$ & $41,976.00$ & $31,913.09$ & \begin{tabular}{|l|}
$141,059.00$ \\
\end{tabular} & $253,865.70$ & $1,519,123.001$ & $1,346,169.20$ \\
\hline Taxi, combi, microbús & $2,059.00$ & $1,051.63$ & $1,662.00$ & $4,550.50$ & $705,603.00$ & $888,561.69$ & $19,577.00$ & $30,293.70$ & $74,734.00$ & $228,236.39$ & $803,633.001$ & $1,152,615,80$ \\
\hline Transporte de carga & $2,109.00$ & $2,262.00$ & $21,018.0 \mathrm{og}$ & 303.00 & 796.100 .00 & $276,056.9 \mathrm{~g}$ & $43,120.00$ & $13,071.60$ & $75,157.00$ & $48,179.18$ & $937,504.00$ & $339,872.70$ \\
\hline Ruta 100 & 240.00 & $1,900.00$ & $5,224.00$ & 366.00 & $6,260.00$ & $5,655,00$ & $8,058.00$ & $6,751.39$ & $2,439.00$ & $2,337.20$ & $22,221.00$ & $17,009.50$ \\
\hline Otros transportes" & 743.09 & $3,307.43$ & $13,313.0 \mathrm{~d}$ & 918.78 & $17,652.00$ & 134,215.65 & $20,960.00$ & $9,755.15$ & $6,991.00$ & $22,780.20$ & $59,659.00$ & $170,977.20$ \\
\hline Total sector transporte & $9,549.00$ & $18,842.06$ & $44,774.00$ & $12,199.79$ & $2,853,748.00$ & $2,248,497,20$ & $133,691.00$ & $\begin{array}{ll}91,786.80 \\
0.00\end{array}$ & $300,380.00$ & $555,318.67$ & $3,342,172.003$ & $3,026,644,40$ \\
\hline Otros sectores & $441,050.00$ & $432,771.00$ & $160,951.00$ & $33,268.30$ & $96,8+9.00$ & $9,641.10$ & $43,648.00$ & $36,859.00$ & $271,721.00$ & $470,441.00$ & $1,014,219.00$ & $982,983.10$ \\
\hline ted sectores & $450,599.00$ & $451,614.0 \mathrm{~d}$ & $205,725.00$ & $45,468.00$ & $2,950,627.00$ & $2,358,141.34$ & $177,339.06$ & $128,646.00$ & $572,101.00$ & $1,025,760.00$ & $4,356,391.00$ & $4,009,629.00$ \\
\hline
\end{tabular}

Inventarios de emisiones: sector transpone 1989 - 1994

\begin{tabular}{|c|c|c|c|c|c|c|c|c|c|c|c|c|}
\hline Tipo de fuente & \multicolumn{12}{|c|}{ Tipo de contaminante (porcentajes en peso por contarninantes) } \\
\hline & \multicolumn{2}{|c|}{ PST } & \multicolumn{2}{|c|}{$\mathrm{SO}_{2}$} & \multicolumn{2}{|c|}{ CO } & \multicolumn{2}{|c|}{ NOx } & \multicolumn{2}{|c|}{ HC. } & \multicolumn{2}{|c|}{ Total } \\
\hline Sector transporte & 1989 & 1994 & 1989 & 1994 & 1979 & 1994 & 1989 & 1994 & 1989 & 1994 & 1959 & 1994 \\
\hline Auto particular & $0.98 \times 0$ & 2.2990 & $1.73 \%$ & $13.33 \%$ & $45.01 \%$ & $44.27 \times 0$ & $23.67 \%$ & $24.81 \%$ & $24.66 \%$ & $24.75 \%$ & $34.87 \%$ & $33.57 \%$ \\
\hline Taxi, combi, microbús & $0.46 \% 9$ & $0.23 \%$ & $0.81 \%$ & $10.01 \%$ & 23.99\% & $37.68 \times 6$ & 11.04\% & 23.55\% & $13.06 \%$ & $22.24 \%$ & 18.45\% & $28.75 \%$ \\
\hline Transporte de carga & $0.47 \% 6$ & $0.50 \% \%$ & $10.22 \%$ & $0.67 \%$ & $26.98 \%$ & 11.7\% & $24.32 \%$ & 10.16\% & 13.14\% & $4.70 \%$ & 21.52206 & $8.48 \%$ \\
\hline Ruta 100 & $0.05 \%$ & $0.42 \mathrm{~m}$ & $2.54 \%$ & $0.80 \%$ & $0.21 \%$ & $0.21 \%$ & $4.5+\%$ & $5.25 \%$ & $0.43 \%$ & $0.23 \times$ & $0.51 \%$ & $0.42 \%$ \\
\hline Otros transportet & $0.16 \%$ & $0.73 \%$ & $6.47 \%$ & $2.02 \%$ & $0.60 \% 2$ & 5.69900 & $11.82 \%$ & $7.58 \%$ & $1.22 \%$ & $2.22 \%$ & $1.37 \%$ & 4.26\% \\
\hline Total sector transporte & 2.1240 & $4.17 \%$ & $21.76 \%$ & $26.83 \%$ & $96.72 \%$ & 99.59\% & 75.3990 & 71.35\% & $52.50 \% \mathrm{~d}$ & $54.14 \times 4$ & 76.720 & $75.48 \%$ \\
\hline Otros sectores & $97.88 \times 9$ & $95.830 \%$ & $78.24 \%$ & $73.17 \%$ & $3.28 \%$ & $0.41 \%$ & $24.61 \%$ & $28.65 \mathrm{mog}$ & 47.50\% & 45.86\% & 23.28\% & $24.52 \%$ \\
\hline Tिस & $1000 \%$ & $1000 \%$ & $100 \% \%$ & $100 \%$ & $100 \%$ & $100 \%$ & 10006 & 10004 & 10004 & $100 \%$ & ioox & $100 \%$ \\
\hline $\begin{array}{l}\text { Fuentes: } \\
\text { (1) Programa Integral Co } \\
\text { (2) Programa para Mejor } \\
\text { PST - Partículas Suspen } \\
\text { SO, - Bíxido de azufre } \\
\text { Co- Monoxido de carb } \\
\text { NOx- Oxidos de nitró }\end{array}$ & $\begin{array}{l}\text { dad d } \\
\text { des }\end{array}$ & & & & & & & & & & & \\
\hline
\end{tabular}




\begin{tabular}{|c|c|c|c|c|}
\hline 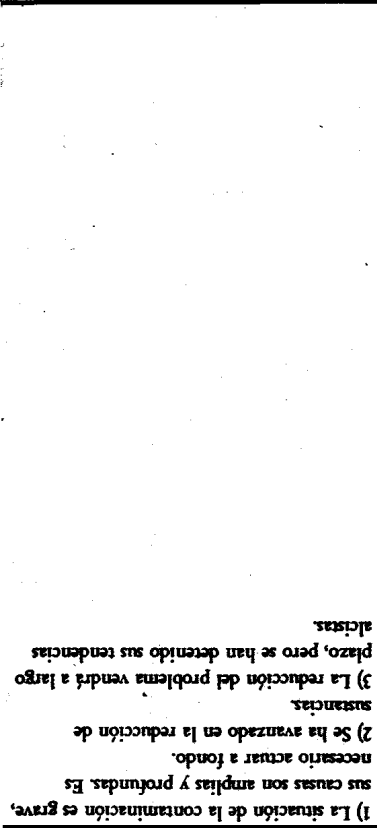 & 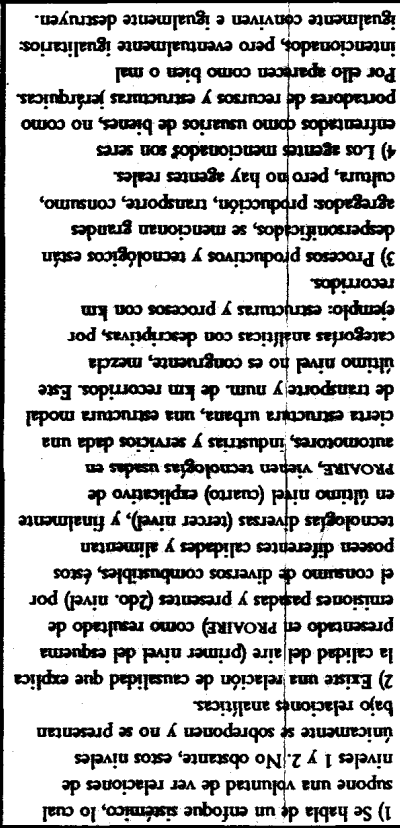 & 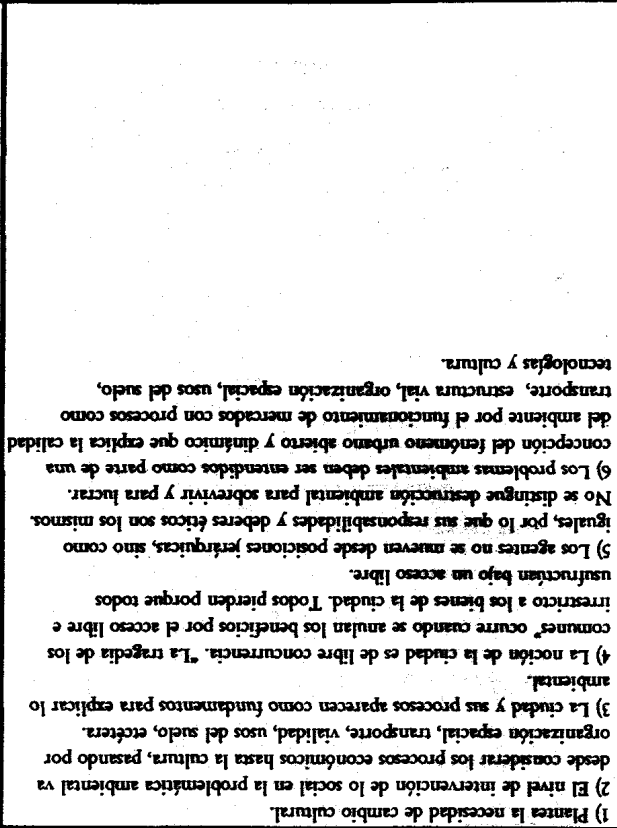 & 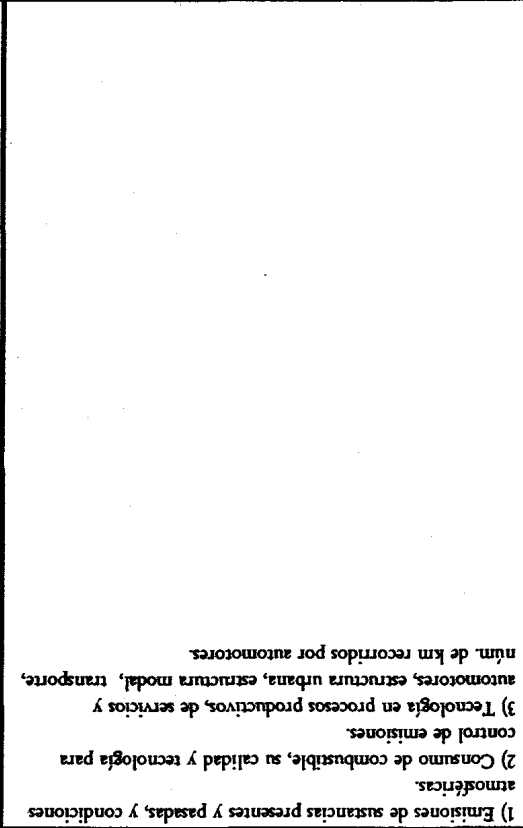 & 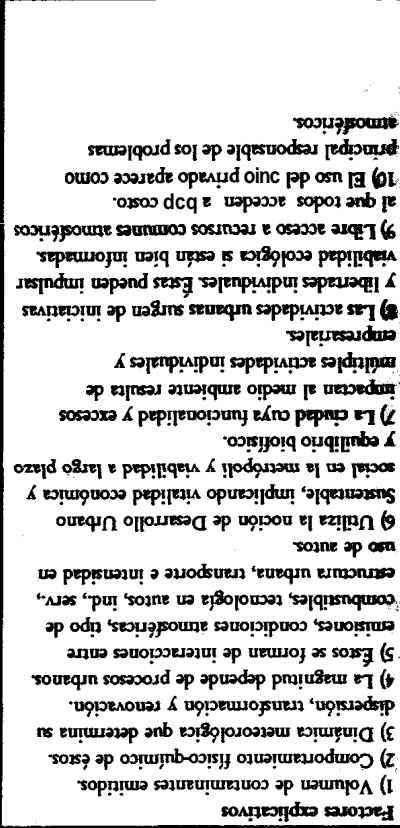 \\
\hline 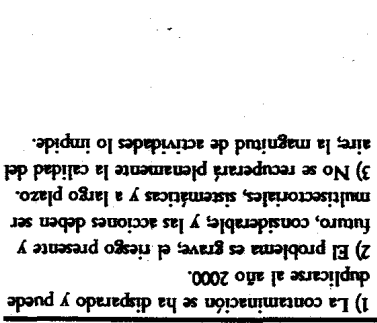 & 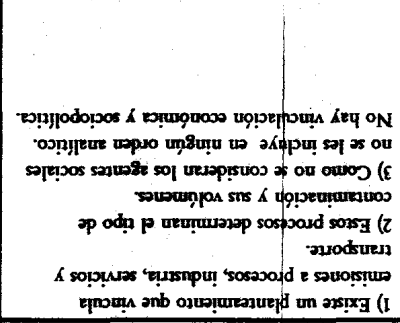 & 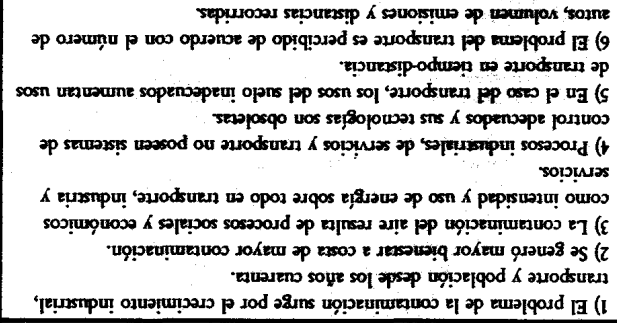 & 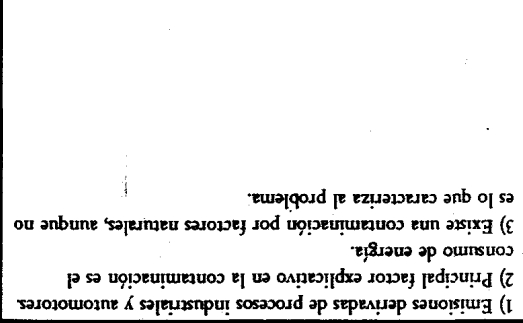 & 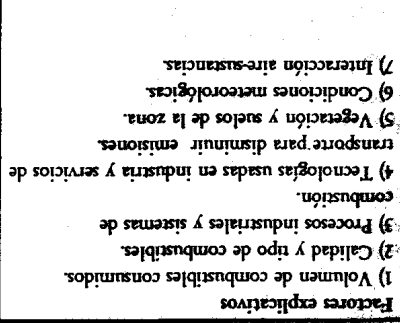 \\
\hline 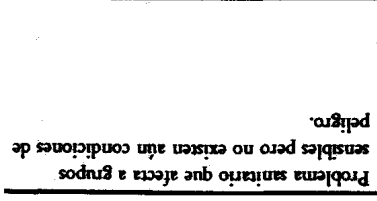 & 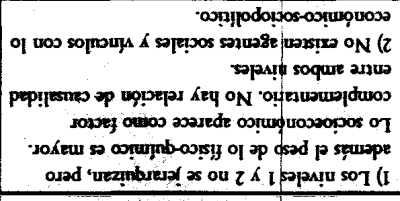 & 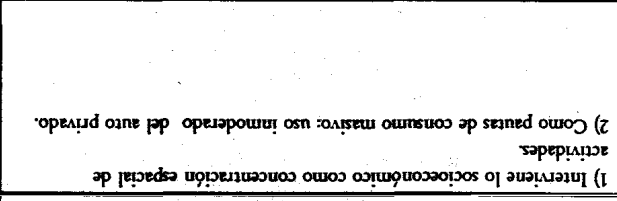 & 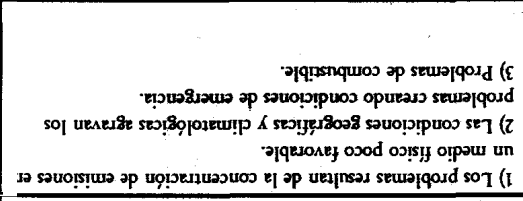 & 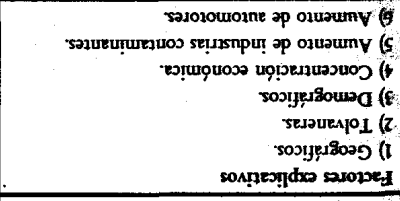 \\
\hline \multirow[t]{2}{*}{ 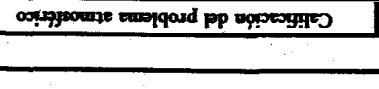 } & 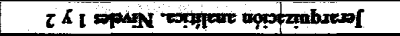 & 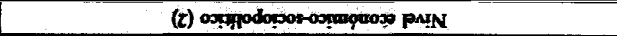 & 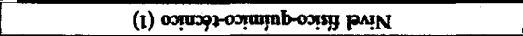 & \multirow{2}{*}{ 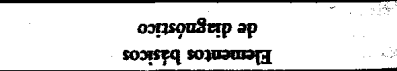 } \\
\hline & & 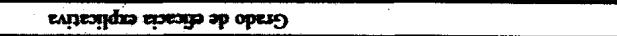 & & \\
\hline
\end{tabular}

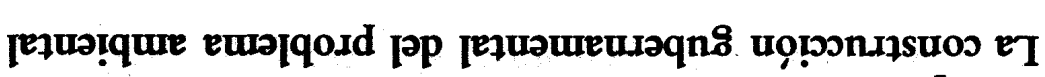

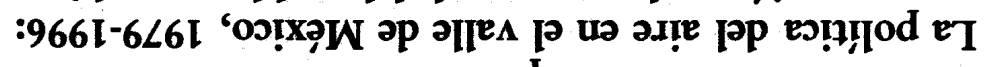

I eurnbs 


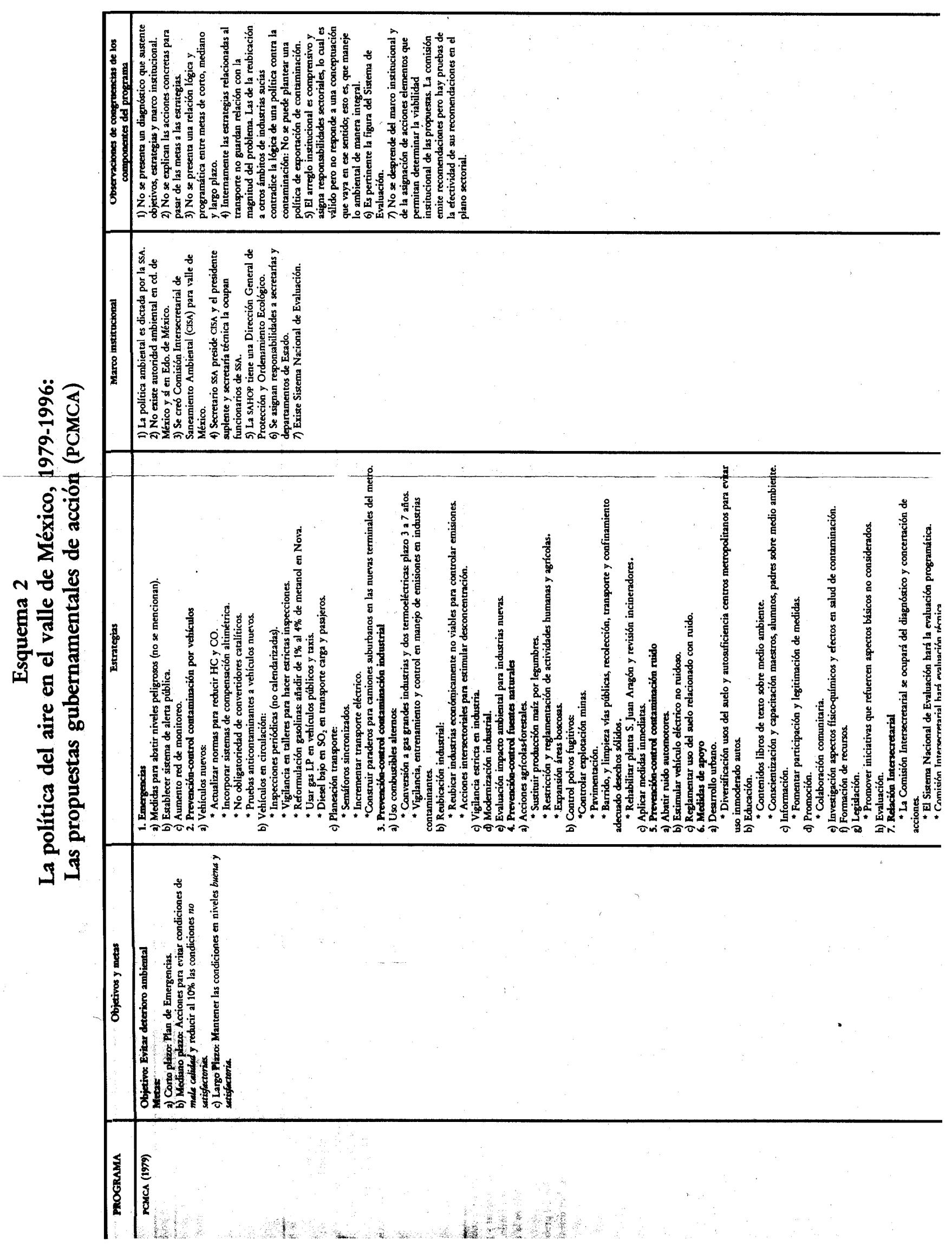




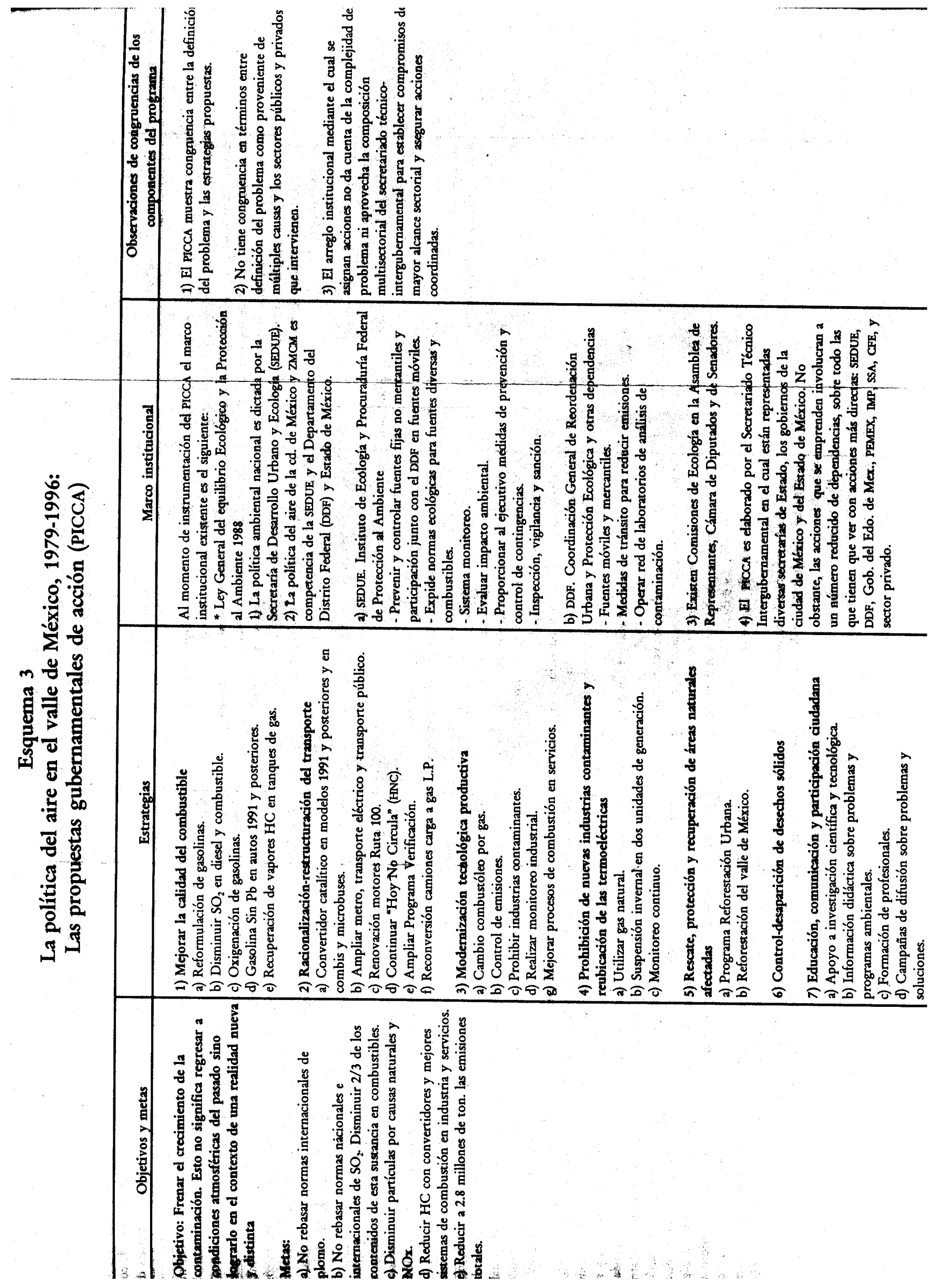


Esquema 4

La política del aire en el valle de México, 1979-1996: Las propuestas gubernamentales de acción (PROAIRE)

\begin{tabular}{|c|c|c|c|}
\hline Objetivos y metas & Estrategias & Marco institucional & $\begin{array}{l}\text { Observaciones de congruencias de los } \\
\text { componentes del programa }\end{array}$ \\
\hline $\begin{array}{l}\text { Objetivo: Obtener cada vez menores niveles de } \\
\text { antaminación por día y menos contingencias por } \\
\text { año con criterios de eficiencia y viabilidad social. } \\
\text { Esto para mejorar la salud de los habitantes } \\
\text { presentes y futuros del valle de México. Para el } \\
\text { año } 2000 \text { tener } 50 \% \text { menos emisiones de HC, } \mathbf{4 0 \%} \\
\text { menos de NOx y } 45 \% \text { de partículas } \\
\text { antropogénicas. } \\
\text { Metas: } \\
\text { a) Industrias limpias, reducción emisiones en } \\
\text { industrias y servicios. } \\
\text { b) Vehículos limpios: disminución de emisiones por } \\
\text { km. } \\
\text { e) Transporte eficiente y nuevo orden urbano: } \\
\text { regulación de km recomdos por vehículos } \\
\text { automotores. } \\
\text { d) Recuperación ecológica: abatimiento de erosión. }\end{array}$ & $\begin{array}{l}\text { Este programa agrupa las estrategias en dos ámbitos: los } \\
\text { de regulación y los de incentivos: } \\
\text { 1) Mejores tecnolog'as en industrias y servicios. } \\
\text { 2) Mejores tecnologías en automotores. } \\
\text { 3) Mejores energéticos en industrias y servicios. } \\
\text { 4) Mayor oferta de transporte de calidad. } \\
\text { 5) Integrar políticas de deśarrollo urbano, } \\
\text { transporte y medio ambiente. } \\
\text { 7) Incentivos económicos. } \\
\text { 8) Inspección y vigilancia industrial y vehicular. } \\
\text { 9) Información y educación ambientalesy } \\
\text { participación social. } \\
\text { Presenta un desglose detallado de acciones en los } \\
\text { siguientes rubros (a los cuales corresponden medidas más } \\
\text { concretas que no se enumeran aquî): } \\
\text { a) Nuevas normas para NOx y CO para industria y } \\
\text { servicios, aś como mejores combustibles. } \\
\text { b) Control de NOx en termoeléctricas. } \\
\text { c) Nueva estructura de precios que favorecen el uso de } \\
\text { mejores combustibles industriales. } \\
\text { d) Incentivos federales para reconversión tecnológica. } \\
\text { e) Modernización del parque vehicular mediante } \\
\text { excepción del HNC a los autos que aprueben normas } \\
\text { más estrictas. } \\
\text { f) Normas cada vez más estrictas para autos nuevos y en } \\
\text { circulación. } \\
\text { g) Mayor cobertura y calidad en verificación. } \\
\text { h) Revisión progresiva de normatividad en gasolinas. } \\
\text { i) Incorporar costos ambientales en gasolinas. } \\
\text { j) Restructurar y ampliar el transporte público. } \\
\text { k) Reorganización del tráfico. } \\
\text { 9 Política de desarrollo urbano con criterio } \\
\text { ambiental. } \\
\text { m) Vigilanaa e información epidemiológica. } \\
\text { n) Vigilancia vial, industrial y de servicio, programa } \\
\text { vehicular. } \\
\text { o) Mecanismos de evaluación, información y auditoría } \\
\text { pública en donde participan distintos sectores sociales, de } \\
\text { gobierno y académicos. } \\
\text { p) Educación ambiental y comunicación social. }\end{array}$ & 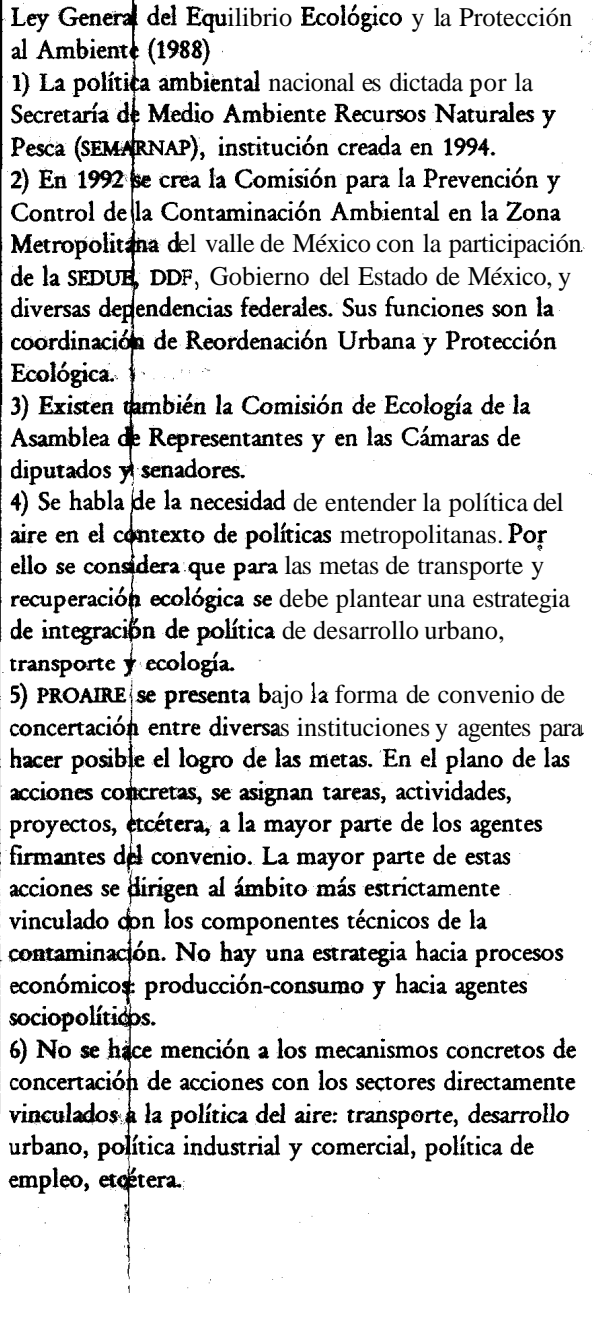 & $\begin{array}{l}\text { 1) PROARE añade mayor número de factores a su } \\
\text { diagnóstico y apunta hacia la idea de sistemas y de } \\
\text { procesos. No obstante, a nivel de propuestas de } \\
\text { política no se arman paquetes de propuestas que } \\
\text { incluyan de manera sistémica y de procesos a los } \\
\text { sectores de la administracióny diversos agentes. } \\
\text { No hay tampoco un tratamiento integral de la } \\
\text { contaminación: aire, agua, suelo, recursos, etcétera. } \\
\text { Por lo tanto, la idea de 'sistemas" sólo es } \\
\text { discursiva. } \\
\text { 2) Estos factores, aun cuando con contenidos de } \\
\text { mayor amplitud analítica, no están vinculadosentr } \\
\text { si. Por ejemplo: no hay secuencia analítica entre } \\
\text { emisiones, procesos económicos y procesos } \\
\text { urbanos. } \\
\text { 3) No hay congruencia entre el enúnciado que } \\
\text { sostiene la necesidad de integración de políticas y } \\
\text { las acciones concretas en el ámbito del desarrollo } \\
\text { urbano y transporte. ¿Cuáles son los componentes } \\
\text { de las políticas de desarrollo urbano y de } \\
\text { transporte que llevan a los objetivos de la política } \\
\text { del aire? } \\
\text { 4) La noción de ciudad, de procesos urbanos y de } \\
\text { agentes sociales, no reproduce el cuadro de fuerzas } \\
\text { políticas, que coexisten y se confrontan en una } \\
\text { ciudad real. Esto no ayuda a una propuesta de } \\
\text { política que plantea redistribuir los costos del } \\
\text { combate a la contaminación. } \\
\text { 5) No hay correspondenciaentre el papel } \\
\text { depredador primordial asignado al auto privado } \\
\text { como causa del deterioro ambiental y el ámbito de } \\
\text { acción de las propuestas correctivas y preventivas. } \\
\text { Éstas deben asignar responsabilidades a los distinto } \\
\text { agentes: productor, distribuidor y consumidor. }\end{array}$ \\
\hline
\end{tabular}


Economía, Sociedad y Territorio, vol. I, núm . 2, 1997, 317-362

\section{Esquema 5 \\ Modelo ideal de análisis e intervención gubernamental}

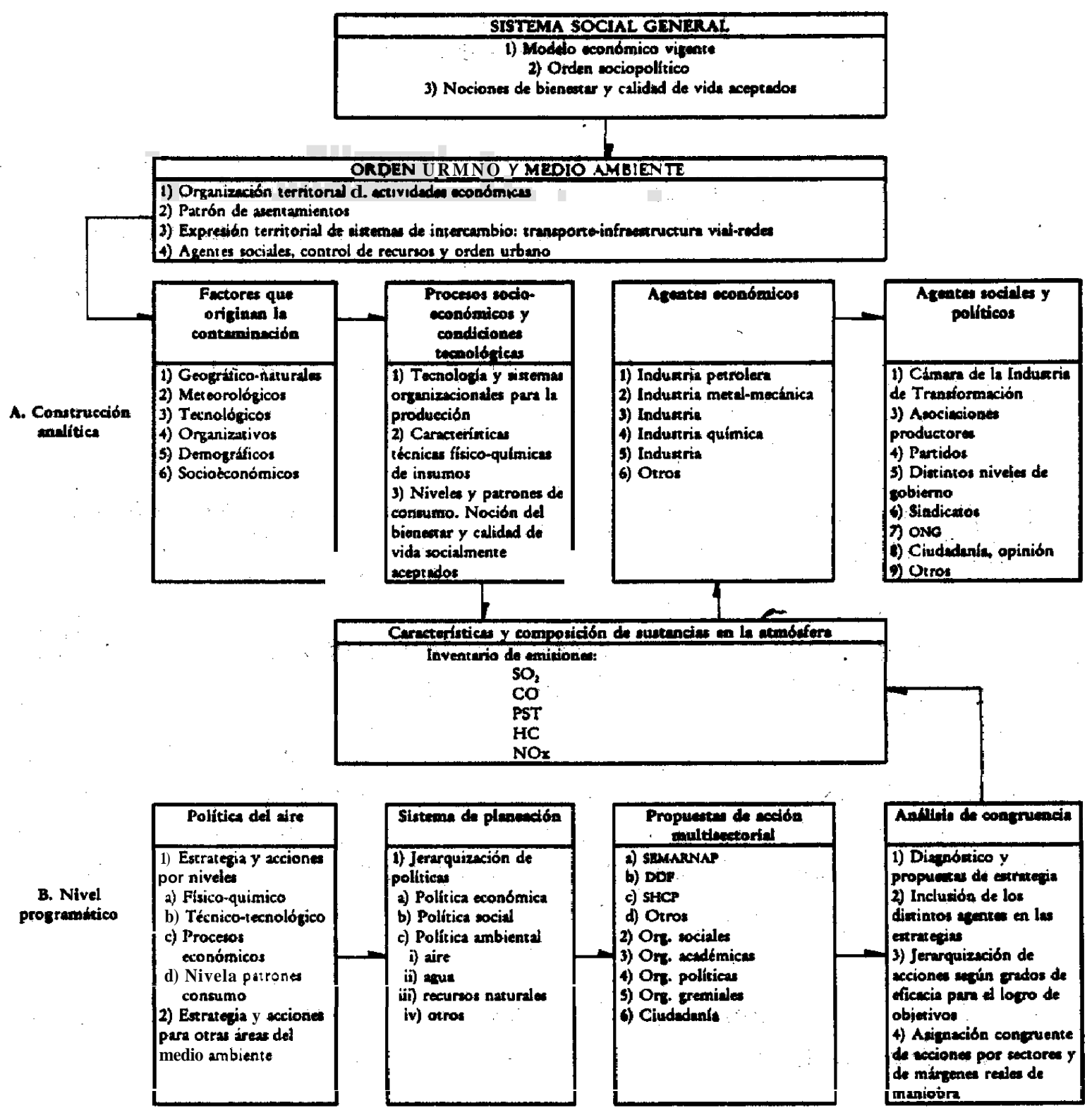




\section{Bibliografía}

Adams, B. (1994), "Sustainable Development and the Greening of Development Theory", en F. J. Schuurman, Beyond the Impasse, Nueva York, Zed Books.

Comisión Intersecretarial de Saneamiento Ambiental (1979), Programa Coordinado para Mejorar la Calidad del Aire (PCMCA), México, Comisión Intersecretarial de Saneamiento Ambiental.

Crenson, M. (1972), The Un-Politics of Air Pollution. A study of Non-Decission Making in tbe Cities, Baltimore, JHUP.

DDF (1990), Programa Integral Contra la Contaminación Atmosférica (PICCA), México, DDF.

DDF et al. (1996), Programa para Mejorar la Calidad del Aire en el Valle de México (PROAIRE), México, DDF.

Lezama, J. L. (1996), "La construcción ideológica y política de la contaminación del aire: consideraciones para el caso de la ciudad de México*, EstudiosDemográficosy Urbanos, vol. 11, núm. 1, enero-abril.

Portney, K. (1992), Controversial Issues in Environmental Policy, Londres, Sage Publications. 